OPEN ACCESS

Edited by:

Cheryl Hawkes,

Lancaster University, United Kingdom

Reviewed by:

Fabrizio Carta

University of Florence, Italy

Yoon Kyung Choi,

Konkuk University, South Korea

*Correspondence:

Silvia Fossati

silvia.fossati@temple.edu

Received: 07 September 2021

Accepted: 20 October 2021

Published: 16 November 2021

Citation:

Lemon N, Canepa E, llies MA and

Fossati S (2021) Carbonic

Anhydrases as Potential Targets

Against Neurovascular Unit

Dysfunction in Alzheimer's Disease

and Stroke.

Front. Aging Neurosci. 13:772278.

doi: 10.3389/fnagi.2021.772278

\section{Carbonic Anhydrases as Potential Targets Against Neurovascular Unit Dysfunction in Alzheimer's Disease and Stroke}

\author{
Nicole Lemon ${ }^{1}$, Elisa Canepa ${ }^{1}$, Marc A. Ilies ${ }^{1,2}$ and Silvia Fossati ${ }^{1 *}$ \\ ${ }^{1}$ Alzheimer's Center at Temple (ACT), Lewis Katz School of Medicine, Temple University, Philadelphia, PA, United States, \\ ${ }^{2}$ Department of Pharmaceutical Sciences and Moulder Center for Drug Discovery Research, Temple University School \\ of Pharmacy, Temple University, Philadelphia, PA, United States
}

The Neurovascular Unit (NVU) is an important multicellular structure of the central nervous system (CNS), which participates in the regulation of cerebral blood flow $(\mathrm{CBF})$, delivery of oxygen and nutrients, immunological surveillance, clearance, barrier functions, and CNS homeostasis. Stroke and Alzheimer Disease (AD) are two pathologies with extensive NVU dysfunction. The cell types of the NVU change in both structure and function following an ischemic insult and during the development of $A D$ pathology. Stroke and AD share common risk factors such as cardiovascular disease, and also share similarities at a molecular level. In both diseases, disruption of metabolic support, mitochondrial dysfunction, increase in oxidative stress, release of inflammatory signaling molecules, and blood brain barrier disruption result in NVU dysfunction, leading to cell death and neurodegeneration. Improved therapeutic strategies for both $A D$ and stroke are needed. Carbonic anhydrases (CAs) are well-known targets for other diseases and are being recently investigated for their function in the development of cerebrovascular pathology. CAs catalyze the hydration of $\mathrm{CO}_{2}$ to produce bicarbonate and a proton. This reaction is important for $\mathrm{pH}$ homeostasis, overturn of cerebrospinal fluid, regulation of $\mathrm{CBF}$, and other physiological functions. Humans express $15 \mathrm{CA}$ isoforms with different distribution patterns. Recent studies provide evidence that CA inhibition is protective to NVU cells in vitro and in vivo, in models of stroke and $A D$ pathology. CA inhibitors are FDA-approved for treatment of glaucoma, high-altitude sickness, and other indications. Most FDA-approved CA inhibitors are pan-CA inhibitors; however, specific CA isoforms are likely to modulate the NVU function. This review will summarize the literature regarding the use of pan-CA and specific CA inhibitors along with genetic manipulation of specific $C A$ isoforms in stroke and $A D$ models, to bring light into the functions of CAs in the NVU. Although pan-CA inhibitors are protective and safe, we hypothesize that targeting specific CA isoforms will increase the efficacy of CA inhibition and reduce side effects. More studies to further determine specific CA isoforms functions and changes in disease states are essential to the development of novel therapies for cerebrovascular pathology, occurring in both stroke and AD.

Keywords: Alzheimer's disease, stroke, carbonic anhydrase (CA), neurovascular unit (NVU), cerebrovascular pathology, amyloid beta, inflammation, mitochondria 


\section{INTRODUCTION}

Neurovascular dysfunction is an important, early and causative event in the pathogenesis of both Alzheimer's disease (AD) and Stroke (Iadecola, 2010, 2017; Hachinski et al., 2019; Sweeney et al., 2019a; Freitas-Andrade et al., 2020; Zlokovic et al., 2020). Indeed, the Neurovascular Unit (NVU) has recently gained a lot of momentum as a pharmacological target in cerebrovascular pathologies and neurodegeneration (Iadecola, 2017; Sweeney et al., 2019a; Zlokovic et al., 2020). The NVU is a functional multicellular structure composed of blood vessels and different cell types surrounding them within the central nervous system (CNS), and is instrumental in regulating CNS homeostasis (Andreone et al., 2015; Iadecola, 2017; Sweeney et al., 2019b; Freitas-Andrade et al., 2020). Important functions of the NVU include regulation of cerebral blood flow (CBF) and immunological surveillance, amongst others (Andreone et al., 2015; Cortes-Canteli and Iadecola, 2020; Freitas-Andrade et al., 2020). NVU dysfunction is observed in aging, $\mathrm{AD}$ and following neurological pathologies such as stroke (Iadecola, 2017; CortesCanteli and Iadecola, 2020; Freitas-Andrade et al., 2020; Sarvari et al., 2020) and traumatic brain injury (Xing et al., 2012; Lok et al., 2015), among others.

Stroke and dementia are the two most common neurological disorders. They confer risks for each other and share some, mostly modifiable, risk factors. Having a stroke doubles the chance of developing dementia (Savva and Stephan, 2010; Kuźma et al., 2018). Therefore, preventing stroke through management of hypertension and other risk factors could also decrease the incidence of dementia (Kuźma et al., 2018; Hachinski et al., 2019).

$\mathrm{AD}$ is the most common form of dementia and has been historically characterized by extracellular amyloid beta $(A \beta)$ plaques and intracellular hyperphosphorylated tau tangles in specific brain regions (Day et al., 2015; Castillo-Carranza et al., 2017; Cortes-Canteli and Iadecola, 2020; Ojo et al., 2021). Interestingly, $A \beta$ and tau intermediate aggregation species, such as oligomers, have been shown to have toxic effects on multiple cell types of the NVU (Fossati et al., 2010, 2012b; Parodi-Rullán et al., 2019; Canepa and Fossati, 2020). This toxicity, in association with the contribution of impaired clearance of undesired material from the brain, may lead to neurodegeneration and cognitive decline (Fossati et al., 2012b; Boland et al., 2018; Da Mesquita et al., 2018; Nortley et al., 2019; Provensi et al., 2019; Braun and Iliff, 2020; Carare et al., 2020; Cortes-Canteli and Iadecola, 2020; Nedergaard and Goldman, 2020; Parodi-Rullán et al., 2020; Quintana et al., 2021). Importantly, up to $90 \%$ of $\mathrm{AD}$ patients also present with cerebral amyloid angiopathy (CAA), defined as $\mathrm{A} \beta$ deposition around the brain vasculature and/or within the vessel walls (Iadecola, 2017; Sweeney et al., 2019a; Zlokovic et al., 2020). CAA is also common in the non-demented elderly population and constitutes an important contributor to NVU dysfunction in both normal aging and AD (Provensi et al., 2019; Cortes-Canteli and Iadecola, 2020; Ojo et al., 2021).

Stroke is classically defined as a neurological damage attributed to an acute focal injury of the CNS by a vascular cause, including cerebral infarction, intracerebral hemorrhage
(ICH), and subarachnoid hemorrhage (SAH), and is a major cause of disability and death worldwide (Sacco et al., 2013). The most common type of stroke is Ischemic Stroke (IS) which occurs when atherosclerotic plaques and fatty deposits cause vascular occlusions, interrupting blood flow in the brain. The blood vessel most commonly occluded is the middle cerebral artery (Kuriakose and Xiao, 2020). When IS occurs, it promptly causes multiple detrimental cerebral injuries due to both the lack of oxygen and glucose, as well as the associated proinflammatory signaling (Faraco et al., 2007; Freitas-Andrade et al., 2020; Kuriakose and Xiao, 2020; Sarvari et al., 2020). Following this event, there is a reperfusion injury phase, which occurs when oxygen and CBF are restored (Faraco et al., 2007; Freitas-Andrade et al., 2020; Sarvari et al., 2020). Another type of stroke is hemorrhagic stroke (HS), which occurs when a blood vessel, providing blood to the brain, ruptures (Corraini et al., 2017; Sarvari et al., 2020). HS is characterized by greater lesion volume, higher intracranial pressure and induce more severe brain injury than IS. Importantly, IS and HS affect different brain regions (Corraini et al., 2017).

Shared risk factors between $\mathrm{AD}$ and stroke are reduced CBF, cardiovascular diseases and age (Sarvari et al., 2020; Ojo et al., 2021). Cardiovascular risk factors like obesity, diabetes, hypertension and atherosclerosis have been observed to exacerbate cerebrovascular pathology as well as neurodegeneration, including AD (Girouard and Iadecola, 2006; de Bruijn and Ikram, 2014; Cortes-Canteli and Iadecola, 2020; Sarvari et al., 2020). The common underlying mechanisms involved in both $\mathrm{AD}$ and stroke include neuroinflammation, mitochondrial dysfunction, cell death, and blood brain barrier (BBB) dysregulation, indicating that the NVU is a target for both diseases (Fossati et al., 2012b; Alluri et al., 2014; Sekerdag et al., 2018; Eldahshan et al., 2019; Provensi et al., 2019; Parodi-Rullán et al., 2020). A vast amount of research has been invested into discovering new treatments for $\mathrm{AD}$ and stroke. In $\mathrm{AD}$, this has recently led to the controversial FDA-approval of aducanumab (Ferrero et al., 2016; Sevigny et al., 2017; Knopman et al., 2021). However, more research needs to be done to develop successful disease-modifying therapies for both disorders. The scientific community is particularly encouraging the study of repurposed drugs, approved by the FDA for other disorders, which could be beneficial for $\mathrm{AD}$ and stroke, while allowing more rapid translation to clinical trials.

This review will introduce the idea of potentially repurposing carbonic anhydrase inhibitors (CAIs), many of which are already FDA-approved for other indications, for prevention of cerebrovascular and neurovascular pathology in $\mathrm{AD}$ and stroke and highlight the impact of carbonic anhydrase (CA) modulation in these two dominant neurological disorders.

CAs are a family of zinc metalloenzymes which catalyze the reversible hydration of carbon dioxide to produce bicarbonate and a proton $\left(\mathrm{CO}_{2}+\mathrm{H}_{2} \mathrm{O} \leftrightarrow \mathrm{HCO}_{3}{ }^{-}+\mathrm{H}^{+}\right)$(Supuran, 2011; Mishra et al., 2020). This chemical reaction is essential for many physiological processes, such as $\mathrm{pH}$ and ion homeostasis, carbon dioxide transport, electrolyte secretion, gluconeogenesis, lipogenesis, and ureagenesis, water and sodium reabsorption in the kidney, bone reabsorption and calcification, cerebrospinal 
fluid formation and turnover, amongst other processes (Provensi et al., 2019; Zamanova et al., 2019; Mishra et al., 2020). CAs have been studied as a well-known pharmacological target for many peripheral and CNS disorders (Bradwell et al., 1992; Ilies et al., 2004; De Simone and Supuran, 2007; Supuran, 2008, 2018; Akocak and Ilies, 2014; Provensi et al., 2019; Zamanova et al., 2019; Mishra et al., 2020). Interestingly, many recent studies revealed a common goal to further elucidate CAs involvement in both $\mathrm{AD}$ and stroke.

Humans have 15 CA isoforms, all with different expression patterns at a tissue and cellular level (Supuran, 2011; Provensi et al., 2019; Zamanova et al., 2019; Mishra et al., 2020). Many of these isoforms are expressed within the NVU and it has been hypothesized that each is involved in different functions (Draghici et al., 2014; Rasmussen and Boedtkjer, 2018; Provensi et al., 2019; Zamanova et al., 2019). It is known that some isoforms are extracellular, anchored to the plasma membrane (CA-IV, CA-IX, and CA-XII, CA-XIV), while others are cytosolic (CA-I, CA-II, CA-III, CA-VII, CA-XIII), two are found in the mitochondria (CA-VA and CA-VB) (Boriack-Sjodin et al., 1995; Nishimori et al., 2005), some are acatalytic isoforms (CA-VIII, CA-X, and CA-XI) (Aspatwar et al., 2014), and one isoform is secreted in saliva (CA-VI) (Nishimori et al., 2007; Alterio et al., 2012; Patrikainen et al., 2014; Provensi et al., 2019; Zamanova et al., 2019; Mishra et al., 2020). CA function has been linked to $\mathrm{AD}$ pathology as well as stroke, but the specific isoforms and the pathological mechanisms involved are not fully understood (Wang et al., 2009; Draghici et al., 2014; Fossati et al., 2016; Pollard et al., 2016; Solesio et al., 2018; Mishra et al., 2020). The determination of each CA isoforms' role in health and disease should be a priority for the development of novel and effective therapies in cerebrovascular pathology (Provensi et al., 2019; Mishra et al., 2020).

CAIs were developed first as diuretics and have become valuable in treating glaucoma, cerebral edema, epilepsy, as well as high altitude sickness (Mincione et al., 2007; Supuran, 2008; Ritchie et al., 2012; Akocak and Ilies, 2014; Zamanova et al., 2019; Mishra et al., 2020). The FDA-approved CAIs methazolamide (MTZ) and acetazolamide (ATZ) are the most studied pan-CAIs. Their activity in the NVU will be one of the focuses of this review. Other FDA-approved CAIs such as topiramate, which has some selectivity for the mitochondrial CA-VA and CA-VB isoforms, along with compounds with selectivity for CA-IX and CA-XII will also be discussed (Scozzafava et al., 2000; Supuran, 2012; Andring et al., 2020; McDonald et al., 2020). MTZ and ATZ, along with topiramate, have been observed to have protective properties on cerebrovascular pathology, as well as on mitochondria function, an important target for NVU integrity (Wang et al., 2009; Price et al., 2012; Fossati et al., 2016; Solesio et al., 2018; Salameh et al., 2019). A substantial amount of literature on the FDAapproved pan-CAIs indicates that they are safe and can pass the BBB. However, the development of new compounds targeting specific isoforms may improve the efficacy and reduce side effects of the already existing pan-CAIs (Provensi et al., 2019; Mishra et al., 2020).

This review will first illustrate the basic structure and functions of the cells composing the NVU, specifically describing how they become dysfunctional in stroke and AD. We will then discuss the properties of multiple CA isoforms and highlight the available evidence showing how CA inhibition may be protective toward multiple dysregulated mechanisms in NVU-composing cells, pointing to CAs as potential targets for both stroke and AD therapy (Provensi et al., 2019; Mishra et al., 2020).

\section{THE NEUROVASCULAR UNIT: FUNCTION AND DYSFUNCTION IN STROKE AND ALZHEIMER'S DISEASE}

\section{The Neurovascular Unit}

The cell types that constitute the NVU (depicted in Figure 1) and collaborate to perform its functions are endothelial cells (ECs), pericytes, smooth muscle cells (SMCs), astrocytes, and microglia (Iadecola, 2017; Freitas-Andrade et al., 2020), which are functionally or physically connected to neurons (Andreone et al., 2015; Cortes-Canteli and Iadecola, 2020; Freitas-Andrade et al., 2020). The NVU is the morpho-functional unit including the $\mathrm{BBB}$, which is important for the transport of nutrients and oxygen from the systemic circulation to the brain, for the clearance of toxic waste from the CNS, for the connection between blood flow and neuronal function, as well as for forming a physical barrier to prevent the entrance of pathogens and other harmful entities into the CNS (Sarvari et al., 2020).

\section{Endothelial Cells}

ECs are essential components of the blood vessel wall. Cerebrovascular ECs form tight and adherent junctions with each other to limit the entry of molecules and cells from the peripheral circulation into the CNS (Reese and Karnovsky, 1967). Transporters expressed on the plasma membrane of ECs specifically regulate what enters and exits the CNS. For example, glucose enters the brain exclusively via transporters, despite the brain being a highly metabolic organ responsible for up to $25 \%$ of total glucose consumption in the body (Tang et al., 2017; Parodi-Rullán et al., 2019). ECs also regulate blood flow by releasing vasodilators and vasoconstrictors, such as nitric oxide (NO) and endothelin-1, respectively (Morikawa et al., 1994; Biernaskie et al., 2001; Freitas-Andrade et al., 2020). Due to the fact that mitochondria are very abundant in cerebrovascular ECs (Oldendorf et al., 1977; Sarvari et al., 2020), these cells are particularly sensitive to oxygen deprivation (Pun et al., 2009; Freitas-Andrade et al., 2020). Hence, pathological conditions which cause oxygen-glucose deprivation (OGD) and prompt excessive reactive oxygen species (ROS) production trigger cerebral endothelial dysfunction, cell death and BBB breakdown (Schreibelt et al., 2007; Pun et al., 2009; Lochhead et al., 2010; Ghiso et al., 2014; Fossati et al., 2016; ParodiRullán et al., 2019; Freitas-Andrade et al., 2020), pointing to the mitochondria as critical targets for EC function and BBB integrity. Efficient communication and exchange of materials between ECs and other cell types of the NVU is essential for CNS homeostasis (Andreone et al., 2015; Freitas-Andrade et al., 2020; Sarvari et al., 2020). 


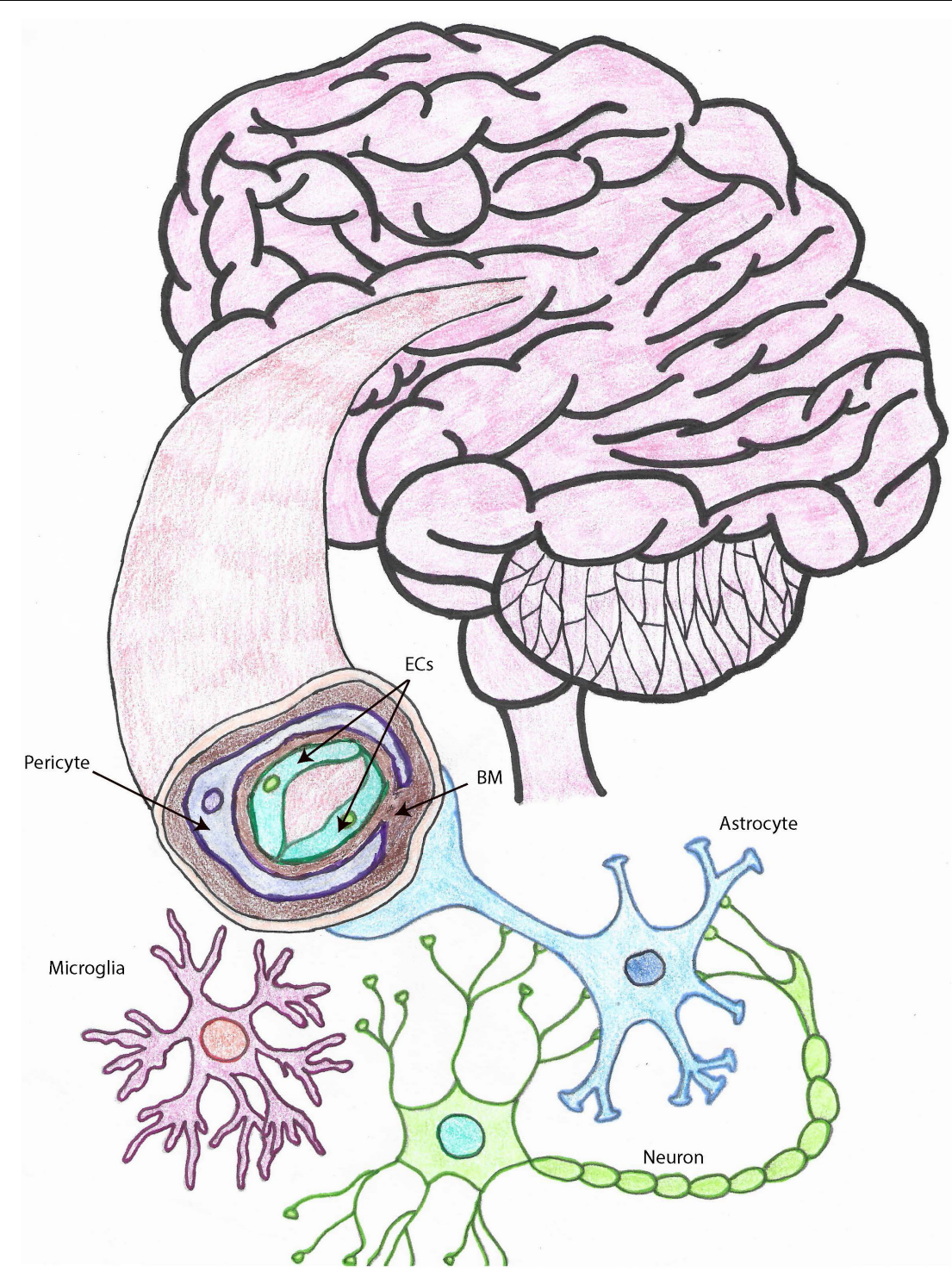

FIGURE 1 | The neurovascular unit. Drawing depicting the cell types that make up the NVU within brain capillaries. Brain capillaries are surrounded by pericytes, as shown in this figure, while arteries and arterioles are surrounded by SMCs. Other important cells associated with blood vessels and important for BBB and neurovascular functions, also represented in this drawing, are astrocytes and microglia. ECs, endothelial cells; SMCs, smooth muscle cells; BBB, blood brain barrier; NVU, neurovascular unit; MCs, microglia cells, BM, basement membrane.

Cerebrovascular dysfunction has been observed in both $\mathrm{AD}$ and IS (Fossati et al., 2010, 2012a,b; Guo et al., 2010; Lochhead et al., 2010; Jiao et al., 2011; Shin et al., 2016; Freitas-Andrade et al., 2020; Parodi-Rullán et al., 2020; Quintana et al., 2021). Aging, as well as cardiovascular risk factors, such as hypertension and diabetes, contribute to cerebrovascular pathology (Huang et al., 1995; Girouard and Iadecola, 2006; Price et al., 2012; Cortes-Canteli and Iadecola, 2020; Ojo et al., 2021). The reduction of tight junction proteins such as zona occludin-1 (ZO1 ) and occludin is observed in models of stroke and $\mathrm{AD}$ (Marco and Skaper, 2006; Jiao et al., 2011; Engelhardt et al., 2014; FreitasAndrade et al., 2020; Parodi-Rullán et al., 2020). An increase in adhesion molecules expression, such as intercellular adhesion molecule-1 (ICAM-1) and vascular cell adhesion molecule-1 (VCAM-1), is observed in stroke, and recently, has been also associated with AD (Cruz Hernández et al., 2019; Sarvari et al., 2020). The reduction of tight junction proteins and the increase in adhesion molecules triggers the recruitment of peripheral immune cells into the brain and may be due to endothelial activation by danger associated molecular patterns (DAMPs), such as low glucose and oxygen, and aggregated proteins, like $\mathrm{A} \beta$ and hyperphosphorylated tau (Canepa and Fossati, 2020; Freitas-Andrade et al., 2020; Sarvari et al., 2020). An increase in $\mathrm{BBB}$ permeability allows peripheral substances to enter the CNS, leading to neuroinflammation and oxidative stress (Pun et al., 2009; Turner and Sharp, 2016; Yang et al., 2019). Increased 
oxidative stress in ECs exacerbates mitochondrial dysfunction, leading to apoptosis (Lochhead et al., 2010; Fossati et al., 2012b, 2016; Solesio et al., 2018; Parodi-Rullán et al., 2019). During both ischemic injury and $\mathrm{AD}, \mathrm{ECs}$ have been observed to decrease NO production, causing dysregulation of CBF (Morikawa et al., 1994; Biernaskie et al., 2001; Girouard and Iadecola, 2006; Austin et al., 2013; Parodi-Rullán et al., 2019; Freitas-Andrade et al., 2020). Interestingly, in endothelial nitric oxide synthase (e-NOS) knockout (KO) mice, deficiency of NO reduces the ability of ECs to neutralize ROS enhancing oxidative stress and neuroinflammation, likely exacerbating $\mathrm{AD}$ pathology (Austin et al., 2013). Accordingly, in models of $A D$ and stroke, EC dysfunction has been shown to enhance neuroinflammation by increasing the production of ROS and enhancing BBB permeability, amongst other cellular mechanisms (Parodi-Rullán et al., 2019, 2020; Yang et al., 2019).

\section{Pericytes and Smooth Muscle Cells}

Pericytes and SMCs surround ECs within the vascular walls, wrapping around capillaries and arterioles/arteries, respectively. Both cell types have a vital role in the regulation of CBF and BBB integrity (Sagare et al., 2013; Hall et al., 2014; Freitas-Andrade et al., 2020). These cells regulate blood flow mainly through their contraction or dilation, which control the diameter of the blood vessel (Hall et al., 2014; Freitas-Andrade et al., 2020). Recently, the role of blood vessels in the clearance of CNS interstitial fluid and proteins has been thoroughly investigated (Aldea et al., 2019; Carare et al., 2020). Intramural periarterial drainage (IPAD) has been hypothesized as a route to drain the brain interstitial fluid and soluble proteins from the CNS into the cervical lymph nodes, by traveling along the capillaries and arterioles in the opposite direction of blood flow, within the basement membrane of the brain vasculature. The contraction of SMCs provides the motive force for IPAD (Carare et al., 2008; Aldea et al., 2019). This system is dysregulated in models of CAA and aging (Ojo et al., 2021). Another brain clearance pathway, the glymphatic system, has been observed to import cerebrospinal fluid along periarterial space and export interstitial fluid along perivenous spaces, in perivascular tunnels, formed by astroglial cells. This pathway has been proposed to be important in the clearance and regulation of toxic proteins in the brain such as tau and $A \beta$, and to be mediated by astrocytic aquaporin-4 (AQP4) (Braun and Iliff, 2020; Nedergaard and Goldman, 2020). Interestingly, the glymphatic system is most efficient during sleep (Boespflug and Iliff, 2018; Mestre et al., 2020).

During both stroke and $\mathrm{AD}$, pericytes are observed to detach from the BBB (Sagare et al., 2013; Freitas-Andrade et al., 2020). In an $\mathrm{AD}$ mouse model, pericyte loss was observed to exacerbate AD pathology (Sagare et al., 2013). The loss of pericytes decreases vascular stability and decreases the ability for the NVU to regulate CBF (Sagare et al., 2013; Hall et al., 2014). On the other hand, a recent study concluded that $A \beta$ induces pericytemediated capillary constriction, reducing CBF (Nortley et al., 2019). Pericytes have been observed to endure damage in models of diabetes as well as obesity, which are both risk factors of $\mathrm{AD}$ and IS (Price et al., 2012; Shah et al., 2013a). In cats exposed to hypoxia, pericytes exhibited detachment from the microvasculature (Gonul et al., 2002). Along with dysregulation of $\mathrm{CBF}$ in models of $\mathrm{AD}$ and stroke, pericyte and SMC loss also contribute to impaired clearance in models of $\mathrm{AD}$ and CAA (Sagare et al., 2013; Aldea et al., 2019; Carare et al., 2020; Kim et al., 2020; Ojo et al., 2021).

\section{Astrocytes}

Astrocytes are essential cells for the NVU and provide a physical connection between blood vessels and neurons (Iadecola and Nedergaard, 2007; Braun and Iliff, 2020). Astrocytic end-feet wrap the blood vessels, helping to stabilize EC tight junctions and regulate CBF (Iadecola and Nedergaard, 2007). Astrocytes play a key role in providing metabolic and physical support to the CNS, along with the regulation of $\mathrm{CBF}$, as well as brain clearance (Freitas-Andrade et al., 2020). AQP4 is a membrane protein that functions in water exchange within the CNS. In healthy individuals, AQP4 is a membrane channel localized at the astrocytic end feet, and it is important for clearance of toxic solutes from the brain (Smith et al., 2019). It is hypothesized that AQP4 is a part of the glymphatic system, mediating fluid exchange and the drainage of proteins, as well as the elimination of liquid from the CNS (Iliff et al., 2012; Boland et al., 2018; Braun and Iliff, 2020; Mestre et al., 2020). Despite the differential contributions of the glymphatic system and the IPAD pathway to the clearance of cerebral fluids and waste material are not completely grasped, it is accepted that astrocytes play a pivotal role in the exchange of fluids, based on studies showing that, in AQP4 KO mice, cerebrospinal fluid influx as well as CNS clearance were decreased (Iliff et al., 2012; Braun and Iliff, 2020). Another essential function of astrocytes is glutamate uptake and release, which is very important for the maintenance of CNS homeostasis (Dejakaisaya et al., 2021; van Putten et al., 2021; Verkerke et al., 2021). Astrocytes also have a critical role in the brain antioxidant system maintenance and in the production of glutathione, an important modulator of oxidative stress and aging (Bains and Shaw, 1997; Venkateshappa et al., 2012; Howarth et al., 2017; Verkerke et al., 2021).

In $\mathrm{AD}$, astrocytes lose their polarization, detach from the $\mathrm{BBB}$, become reactive and release inflammatory cytokines (Liddelow et al., 2017; Sweeney et al., 2019b; Cortes-Canteli and Iadecola, 2020). The crosstalk between astrocytes and microglia needs further understanding, although it has been extensively shown that they modulate each other's activation state (Joshi et al., 2019; McConnell et al., 2019; McAlpine et al., 2021). Astrocytes have also been reported to lose their expression of AQP4 early in AD (Smith et al., 2019). Differently, in stroke, AQP4 expression correlates with cerebral edema, increasing neuronal damage (Manley et al., 2000). In IS, astrogliosis is very significant due to the presence of DAMPs during the initial/acute phase, as well as the secondary/later phase of injury. A major indicator of gliosis is an increase in the expression of glial fibrillary acidic protein (GFAP) by astrocytes, observed in stroke as well as AD models (Pekny and Lane, 2007; Oeckl et al., 2019; Freitas-Andrade et al., 2020). Upon ischemic injury, neurovascular coupling is lost, together with astrocyte mediated CBF (McConnell et al., 2019; Freitas-Andrade et al., 2020). This results in a loop of metabolic stress and inflammation, worsening mitochondrial 
dysfunction in vascular cells, and ultimately leading to $\mathrm{BBB}$ breakdown (Girouard and Iadecola, 2006; Freitas-Andrade et al., 2020; Radenovic et al., 2020; Sarvari et al., 2020).

\section{Microglia}

Although not directly attached to ECs, microglia mediate BBB integrity (Eldahshan et al., 2019; Freitas-Andrade et al., 2020). They are considered the resident immune cells of the CNS, able to phagocytize neurotoxic substances, and, more recently, they have also been reported to participate in a series of cerebral homeostatic functions, including synaptic plasticity and brain development (Badimon et al., 2020; Willis et al., 2020). There are two well-studied activation phenotypes of microglia, referred as M1 and M2, which are classified as being pro-inflammatory and anti-inflammatory, respectively. The M1 phenotype is detrimental to the $\mathrm{BBB}$, causing dysregulation of the $\mathrm{NVU}$, while the M2 facilitates the endocytosis and the clearance of toxic substances and dying cells, limiting the amount of oxidative stress and promoting a more suitable environment for regeneration/healing, following CNS injury (Tang and Le, 2016; Freitas-Andrade et al., 2020; Jiang et al., 2020). Recently, a protein highly expressed in microglia, triggering receptor expressed on myeloid cells-2 (TREM2), has been observed to protect from neurodegeneration in models of AD. TREM2 is hypothesized to be neuroprotective, associated with the M2 phenotype, although there are variants that increase the likelihood of developing $\mathrm{AD}$ (Ulland and Colonna, 2018; Gervois and Lambrichts, 2019; Zhou et al., 2020). The protective mechanisms of TREM2 have also been observed in IS (Gervois and Lambrichts, 2019).

Following IS or HS, microglia transition into a reactive state, causing the release of pro-inflammatory cytokines, exacerbating neuroinflammation and neurovascular dysfunction (Eldahshan et al., 2019). Microglia activation is also observed in models of $\mathrm{AD}$ and is now considered one of the major hallmarks of the disease (Villegas-Llerena et al., 2016). Inflammasome activation has been observed to occur in aging, neurodegeneration, as well as in stroke (Mohamed et al., 2015; Liddelow et al., 2017; Hu et al., 2019; Yang et al., 2019). In the brain, inflammasome activation occurs in many different cell types. Particularly, microglia, being the most sensitive cells to pathogen associated molecular patterns (PAMPs) and DAMPs, trigger the activation of caspase- 1 and the release of cytokines IL-1 $\beta$ along with IL-18 (Hu et al., 2019). The cytokine receptors on vascular cells are then activated, triggering detrimental processes which cause NVU dysfunction and disruption of neurovascular coupling (Eldahshan et al., 2019). Among other cells, microglia have also been observed to secrete metalloproteases (MMPs), such as matrix metallopeptidase-2 (MMP-2) and matrix metallopeptidase-9 (MMP-9), which have been reported to be activated in $\mathrm{AD}$ and IS, degrading the basement membrane, therefore increasing BBB permeability and NVU dysfunction (Lorenzl et al., 2003; Hernandez-Guillamon et al., 2010; Yang and Rosenberg, 2015; Turner and Sharp, 2016; Montaner et al., 2019; Freitas-Andrade et al., 2020; Sarvari et al., 2020; Carcel-Marquez et al., 2021).

\section{Basement Membrane}

The basement membrane is an essential part of the BBB and is composed of numerous proteins such as laminins, collagen, nidogen, and heparin sulfate proteoglycans (Carare et al., 2020). The different proteins that make up the basement membrane are secreted by the cell types composing the NVU such as ECs, pericytes and astrocytes. These different proteins support cellcell interactions, and thus BBB integrity (Carare et al., 2020; Freitas-Andrade et al., 2020).

Destruction of the basement membrane is severely apparent after middle cerebral artery occlusion (MCAO) (Sarvari et al., 2020). This degeneration occurs through different mechanisms of neuroinflammation such as ROS production as well as MMP secretion (Mohamed et al., 2015; Yao, 2019; Freitas-Andrade et al., 2020). Furthermore, the secretion and activation of MMPs interferes with the composition of the $\mathrm{BBB}$, causing it to become leaky, and further exacerbating already existing oxidative stress and neuroinflammation (Fujimura et al., 1999; HernandezGuillamon et al., 2010; Montaner et al., 2019; Kang and Yao, 2020). Basement membrane composition and structure has also been observed to change in models of CAA (Morris et al., 2014).

\section{Neurons}

Blood vessel-coupled-neurons communicate with ECs and other cells of the NVU to modulate vascular structure, dilation or constriction, and to provide nutrients based on neuronal need (Andreone et al., 2015; Iadecola, 2017; Kaplan et al., 2020). Neurovascular coupling is essential to maintain the proper influx of nutrients and the proper efflux of toxic waste from the brain (Girouard and Iadecola, 2006; Andreone et al., 2015; Kaplan et al., 2020). Neuronal activity has been observed to participate in both angiogenesis and neurovascular coupling (Girouard and Iadecola, 2006; Huneau et al., 2015).

Upon CNS injury and cell death of NVU cells, dysregulation of neurovascular coupling occurs (Iadecola, 2017; Sweeney et al., 2019a; Freitas-Andrade et al., 2020; Kaplan et al., 2020). The absence of communication between the CNS and the systemic blood circulation ultimately leads to metabolic failure, oxidative stress, mitochondrial dysfunction and synaptic loss (FreitasAndrade et al., 2020; Kaplan et al., 2020). It is therefore conceivable that, when cerebrovascular integrity and function are preserved, neurodegeneration is less severe and CNS homeostasis is better maintained.

\section{CARBONIC ANHYDRASES}

CAs are a family of zinc metalloenzymes catalyzing the reversible reaction $\mathrm{CO}_{2}+\mathrm{H}_{2} \mathrm{O} \rightleftharpoons \mathrm{HCO}_{3}{ }^{-}+\mathrm{H}^{+}$. All four species in this chemical reaction are essential for CNS homeostasis. Therefore, it is expected that CAs influence CNS and further NVU function. The $\mathrm{CO}_{2}$ hydration reaction can occur spontaneously (uncatalyzed), but the reaction rate is too slow for the dynamic of living cells. Consequently, CA is ubiquitously spread in all living organisms, including humans, where it accelerates this reaction millions of times, making the interconversion of $\mathrm{CO}_{2}$ and $\mathrm{HCO}_{3}{ }^{-}$almost instantaneous. In humans, there are $15 \mathrm{CA}$ isoforms, either acatalytic (CA-VIII, CA-X, and CA-XI) with exact function presently unknown, or catalytically active. The latter are found in the subcellular locations where $\mathrm{CO}_{2} / \mathrm{HCO}_{3}-$ interconversion is required, from the site of production in 
the mitochondria (mitochondrial CA-VA and CA-VB), moving into the cytosol (CA-I, CA-II, CA-III, CA-VII, CA-XIII), then to the plasma membrane (CA-IV, CA-IX, CA-XII, CA-XIV) and finally extracellularly (CA-VI secreted in saliva (Supuran, 2008; Zamanova et al., 2019; Mishra et al., 2020). As genetic manipulation and selective inhibitors (Supuran et al., 1998; Ilies et al., 2003; Smaine et al., 2007; Supuran, 2008; Güzel et al., 2009; Winum et al., 2009; Alterio et al., 2012; Akocak et al., 2016; Angeli et al., 2020) have become more available, there has been an increase in studies to determine the cellspecific function of different CA isoforms (Ghandour et al., 1992; Sly and Hu, 1995; Kida et al., 2006; Pan et al., 2006, 2012; Imtaiyaz Hassan et al., 2013; Shah et al., 2013b; Akocak and Ilies, 2014; Angeli et al., 2017; Waheed and Sly, 2017; Haapasalo et al., 2020; Mishra et al., 2020). One of the most ubiquitously expressed and catalytically active isoform is CA-II, having a turnover rate for $\mathrm{CO}_{2}$ hydration approaching diffusion limit $\left(\mathrm{K}_{\text {cat }}=1.4 \times 10^{6} \mathrm{~s}^{-1}\right)$. It is a cytosolic enzyme and has the widest distribution in the human body, being expressed in cells from virtually every tissue or organ. In the brain, it is found in large amounts in oligodendrocytes and epithelium of the choroid plexus. Subjects suffering from CA-II deficiency syndrome, a human autosomal recessive disorder, display osteopetrosis, bone fragility, renal tubular acidosis, and, importantly, cerebral calcification and cognitive defects, developmental delay and usually a short stature (Sly and Hu, 1995; Supuran, 2008; Zamanova et al., 2019; Mishra et al., 2020). This isoform has been observed to translocate to the mitochondria, upon aging and neurodegeneration in a Purkinje cell degeneration mouse model (Pollard et al., 2016). This study also showed that C. elegans exposed to CA-II have a shorter lifespan, suggesting that high CA-II levels are involved in cell life/cycle-limiting mechanisms. Future studies need to further elucidate why and how this occurs.

CA-I isoform was first identified in red blood cells, where is five to six times more abundant than CA-II, although it has only about $15 \%$ of the CA-II activity (Supuran, 2008; Zamanova et al., 2019; Mishra et al., 2020). CA-I is the most abundant non-hemoglobin protein in erythrocytes and, together with CA-II, contributes to equilibration of dissolved $\mathrm{CO}_{2} / \mathrm{HCO}_{3}{ }^{-}$ pools in blood and maintains the $\mathrm{pH}$ blood homeostasis, also facilitating the $\mathrm{CO}_{2}$ transport from brain and metabolizing tissues to lungs (Sly and Hu, 1995; Supuran, 2008; Zamanova et al., 2019; Mishra et al., 2020). CA-I is hypothesized to contribute to cerebral edema due to the observation that CAI is increased in the brain following HS (Guo et al., 2012). One of the most important cytosolic isozymes in the brain is CA-VII, a fast isozyme $\left(\mathrm{K}_{\text {cat }}=9.5 \times 10^{5} \mathrm{~s}^{-1}\right)$, found especially in the neurons of hippocampus, together with CAII. Interestingly, CA-VII is not found in glial cells, which contain just CA-II in the cytosol. Besides CNS, CA-VII is found in skeletal muscles, stomach, duodenum, liver, colon (Sly and Hu, 1995; Supuran, 2008; Zamanova et al., 2019; Mishra et al., 2020). In the brain, Kaila's group has shown that CA-VII acts as a molecular switch in hippocampal CA1 pyramidal neurons in the development of synchronous gammafrequency firing in response to high-frequency stimulation. This finding makes CA-VII an important modulator of long-term potentiation, synaptic plasticity, memory, and learning processes (Ruusuvuori et al., 2004). The same group, using a novel CAVII (Car7) KO mouse model, as well as a CA-II (Car2) KO, and a CA-II/VII double KO mouse models, has shown that in mature hippocampal pyramidal neurons CA-VII and CAII isozymes enhance bicarbonate-driven GABAergic excitation during intense $\mathrm{GABA}_{A}$-receptor activation. The expression of these two cytosolic isozymes was detected at a very early age in the animals (10- and 20-days post-birth), pointing toward CA-VII and CA-II being key molecules in age-dependent neuronal pH regulation (Supuran, 2008; Ruusuvuori et al., 2013; Ruusuvuori and Kaila, 2014; Zamanova et al., 2019; Mishra et al., 2020).

Membrane-bound isozymes also play an important role in the brain, especially for the regulation of extracellular $\mathrm{pH}$ (Chesler, 2003; Shah et al., 2005). Thus, the phosphatidylinositol glycan (GPI)-anchored isozymes CA-IV (Stams et al., 1996) is a fast isozyme $\left(\mathrm{K}_{c a t}=1.1 \times 10^{6} \mathrm{~s}^{-1}\right)$ found on the plasma face of the cortical capillaries. It is more resistant to inhibition by halide ions than CA-II, being adapted to perform the $\mathrm{CO}_{2} / \mathrm{HCO}_{3}{ }^{-}$ interconversion in the extracellular space that contains a higher concentration of $\mathrm{Cl}^{-}$ions than the cytosol. The isozyme is also expressed in the choriocapillaries of the eye, in skeletal and cardiac muscles, lungs, kidneys, gastrointestinal and reproductive tracts (Sly and Hu, 1995; Supuran, 2008; Zamanova et al., 2019; Mishra et al., 2020). Another isoform localized within the plasma membrane is CA-IX, a transmembrane isozyme, possessing an $\mathrm{N}$-terminal proteoglycan domain, the catalytic domain, a singlepass transmembrane region, and an intracellular tail. It is a dimeric protein with a low expression pattern in most organs, except for the digestive system (largest amount) and CNS, where it can be found mainly in the ventricular-lining cells and in the choroid plexus (Saarnio et al., 1998; Hilvo et al., 2008; Supuran, 2008; Alterio et al., 2009; Pastorek and Pastorekova, 2015; Zamanova et al., 2019; Mishra et al., 2020). The expression of CA-IX is up-regulated in hypoxia by the transcription factor hypoxia inducible factor-1 (HIFl $\alpha$ ) and is associated with the Warburg effect in cancer pathology (Ivanov et al., 2001; Supuran, 2008; Pastorek and Pastorekova, 2015; Shabana and Ilies, 2019). In models of glioblastoma, CA-IX has been observed to increase cell migration, motility, and adhesion in monocytes (Huang et al., 2020). Currently, a compound partially selective to inhibit for CA-IX, referred to as SLC-0111, is in clinical trials, and it is likely it would operate as a therapy for multiple cancers, including glioblastoma (Boyd et al., 2017; Ilies and Winum, 2019; Shabana and Ilies, 2019; McDonald et al., 2020). This isoform has also been suggested to be involved in heart fibrosis in a rat cardiac ligation model (Vargas et al., 2016). Interestingly, in humans, CA-IX is expressed also within atherosclerotic plaques, where it is suggested to be a marker of necrotic tissue (Demandt et al., 2021). Recent studies provided evidence that CA-IX likely exacerbates cerebral ischemia outcomes (Mishra et al., 2020). CA-XII is another medium-fast $\left(\mathrm{K}_{c a t}=4.2 \times 10^{5} \mathrm{~s}^{-1}\right)$, membrane-bound isozyme, similar in general structure with CAIX, but without the proteoglycan domain. It is also dimeric, with the two active sites oriented toward the extracellular milieu 
(Ivanov et al., 1998; Türeci et al., 1998; Whittington et al., 2001). It is found in many hypoxic tumors, alongside CAIX, including gliomas, hemangioblastomas, and meningiomas. However, opposite to CA-IX, CA-XII is highly expressed in many normal tissues including breast epithelium and nonpigmented ciliary epithelial cells of the eye, in brain (small peripheral capillaries), esophagus, pancreas, colon, rectum, kidney, prostate, ovary, testis, endometrium, sweat glands. CAXII was shown to play a key role in epithelial cell electrolyte homeostasis via activation of the ductal $\mathrm{Cl}^{-} / \mathrm{HCO}_{3}{ }^{-}$exchanger AE2, and association with $\mathrm{Na}^{+} / \mathrm{HCO}_{3}{ }^{-}$cotransporter $\mathrm{kNBC} 1$ (Proescholdt et al., 2005; Purkerson and Schwartz, 2007; Supuran, 2008; Hong et al., 2015; Waheed and Sly, 2017; Zamanova et al., 2019; Mishra et al., 2020). The membrane-bound isozyme CA-XIV possesses an extracellular catalytic domain, a single transmembrane helix, a short intracellular polypeptide segment, and has a moderate catalytic activity. It is highly expressed in the kidney, retina and the heart, as well as in brain, skeletal muscles, liver, and lungs. It was reported that CA-XIV is interacting with bicarbonate transporters and is involved in acid-base balance in muscles and erythrocytes in response to chronic hypoxia, and hyperactivity of the heart (Mori et al., 1999; Supuran, 2008; Mboge et al., 2018; Zamanova et al., 2019; Mishra et al., 2020).

The mitochondrial isoforms CA-VA and CA-VB are isozymes with medium-high activity $\left(\mathrm{K}_{\text {catVA }}=2.9 \times 10^{5} \mathrm{~s}^{-1}\right.$, $\mathrm{K}_{\text {cat } V B}=9.5 \times 10^{5} \mathrm{~s}^{-1}$ ), important for gluconeogenesis, lipogenesis, ureagenesis, and other anabolic pathways. They supply $\mathrm{HCO}_{3}{ }^{-}$to pyruvate carboxylase during gluconeogenesis and lipogenesis pathways, and to carbamoyl phosphate synthetase in ureagenesis pathway. CA-VA is found mainly in the liver, while CA-VB is found in skeletal and heart muscles, kidneys, pancreas, gastrointestinl tract, brain and spinal cord (Shah et al., 2000; Supuran, 2008; Scozzafava et al., 2013; Zamanova et al., 2019; Mishra et al., 2020). Due to their involvement in these anabolic pathways, they have been studied in models of obesity and type 2 diabetes (De Simone and Supuran, 2007; Supuran, 2012; Scozzafava et al., 2013; Salameh et al., 2019; Mishra et al., 2020). The function of CA-V and the difference between CA-VA and CA-VB isoforms has been examined by analyzing the phenotypical differences between CA-VA and CA$\mathrm{VB} \mathrm{KO}$, as well as the double $\mathrm{KO}$ mouse models, indicating their role in ammonia detoxification (Shah et al., 2013b). The function of CA-V in the brain is extremely understudied, however, CA-VA has been reported to be expressed in both neurons and glial cells (Ghandour et al., 2000). Interestingly, the effect of CA-V has been also investigated in cerebral pericytes (Price et al., 2017). It has been observed that silencing of both isoforms protect against high-glucose-induced cell death and ROS production, CA-VA to a more significant degree (Price et al., 2017), confirmed also by increased oxidative stress and apoptosis in models of CA-VA over expression (Price et al., 2017).

Although extensive studies reported the multiple functions of the different CA isoforms in a variety of tissues, further investigation regrading CAs cell-specific expression/activity, especially within the CNS, and in CNS disorders, is needed. In particular, CAs impact on cerebrovascular dysregulation occurring during IS and $\mathrm{AD}$ must still be elucidated. It is therefore crucial to identify the cell- and isoform-specific roles, and to design isoform-selective inhibitors, which may be likely to ameliorate the cell/tissue specificity and to decrease the observed side effects of the FDA-approved pan-CAIs (Provensi et al., 2019; Zamanova et al., 2019; Mishra et al., 2020).

Below, we summarize the available literature highlighting the positive effects of CA inhibition on neurovascular dysfunction in stroke-, AD-, CAA-, and diabetes-induced cerebrovascular pathology.

\section{Carbonic Anhydrase Inhibitors and Cerebrovascular Pathology}

CAIs have been studied for decades (Maren, 1967; Bertini and Luchinat, 1983; Silverman and Lindskog, 1988; Supuran et al., 2003; Krishnamurthy et al., 2008; Supuran, 2008; Winum et al., 2009; Alterio et al., 2012; Akocak and Ilies, 2014; McKenna and Supuran, 2014; Supuran and Winum, 2015; Ilies and Winum, 2019; Angeli et al., 2020; Supuran and Capasso, 2020). They were first developed as diuretics due to their function on the reabsorption of sodium and water within the kidney (DuBose, 1984; Purkerson and Schwartz, 2007; Supuran, 2018), and are currently used to treat glaucoma as they decrease intraocular pressure, and for the prevention of high altitude sickness (Bradwell et al., 1992; Mincione et al., 2007; Ritchie et al., 2012), as they diminish pulmonary vasoconstriction, increase CBF likely controlling cerebral oxygenation, and reduce cerebral edema (Mishra et al., 2020). However, the molecular mechanism responsible for the effects of CAIs, including some of the most used pan-CAIs such as ATZ and MTZ, are multiple, and still under investigation.

MTZ, for example, was recognized as one of a few compounds that had the ability to inhibit cytochrome $c$ release from the mitochondria under oxidative stress (Wang et al., 2008). Over 1000 compounds of the NINDS drug library were first screened in isolated mitochondria from mouse liver and further confirmed in striatal cells in models of Huntington's disease. MTZ, inhibiting cytochrome $\mathrm{c}$ release from challenged mitochondria, also resulted in the reduction of caspase- 9 and caspase- 3 activation (Wang et al., 2008; Fossati et al., 2016; Sekerdag et al., 2018). Following this study, FDA-approved CAIs such as MTZ, ATZ, topiramate and more recently developed non-FDA approved selective inhibitors, are starting to be applied in models of cerebrovascular pathology, ischemia, CAA and $\mathrm{AD}$, and their positive effects have been attributed, at least in part, to their ability to prevent mitochondrial dysfunction in cerebrovascular cells (Wang et al., 2009; Shah et al., 2013a; Fossati et al., 2016; Solesio et al., 2018).

CA inhibition has been shown to contribute to cerebrovascular tone during transient phases of $\mathrm{pH}$ change, but not in steady-state conditions, in rat arteries (Rasmussen and Boedtkjer, 2018). This study used two different CAIs, ATZ and 4-aminomethylbenzenesulfonamide (AMB). It was revealed that only the pan-CAI ATZ, potent against most of intracellular CA isozymes, had an effect on intracellular acidification mechanisms. Based on the observed results, it was concluded that intracellular CAs are responsible for modifying the rate of intracellular $\mathrm{pH}$ and vascular tone within the arteries (Rasmussen and Boedtkjer, 2018). Other studies have observed the vasodilator 
abilities of ATZ, such as increased NO production leading to increased blood flow in the cortex of rats (Tuettenberg et al., 2001). It is likely that the production of NO is not the only mechanism by which ATZ mediates vasodilation (Kiss et al., 1999). Systemic administration of ATZ has also been widely used as a short test to increase CBF in human studies (Okudaira et al., 1995; Grossmann and Koeberle, 2000; Russell et al., 2008). Interestingly, its stimulatory effect on CBF is reduced in patients with $\mathrm{AD}$ or vascular dementia compared to healthy controls (Stoppe et al., 1995; Pavics et al., 1999).

\section{Carbonic Anhydrase Inhibition in Models of Ischemic Stroke}

The neuroprotective effects of MTZ, in both in vitro and in vivo models of ischemic injury, displayed in Table 1, were first explored by Wang et al. (2009). Exposing primary cortical neurons to $\mathrm{OGD}$ and $\mathrm{H}_{2} \mathrm{O}_{2}$ resulted in necrosis, which

TABLE 1 | CA inhibition in models of IS.

\begin{tabular}{|c|c|c|c|}
\hline Model & Mechanism & $\begin{array}{c}\text { CA } \\
\text { Inhibitor/Isoform }\end{array}$ & References \\
\hline $\begin{array}{l}\text { Mouse primary } \\
\text { cortical neurons }\end{array}$ & $\begin{array}{l}\text { Inhibition of OGD } \\
\text { induced necrosis } \\
\text { Inhibition of OGD } \\
\text { induced mitochondria } \\
\text { mediated apoptosis } \\
\text { Inhibition of OGD } \\
\text { induced inflammasome } \\
\text { activation }\end{array}$ & MTZ & $\begin{array}{l}\text { Wang et al., } \\
2009\end{array}$ \\
\hline $\begin{array}{l}\text { C57BL/6J } \\
\text { Mouse pMCAO }\end{array}$ & $\begin{array}{l}\text { Reduction of infarct size } \\
\text { Improvement of } \\
\text { neurological score } \\
\text { Reduction of caspase } 3 \\
\text { activation } \\
\text { Decrease of } \\
\text { cytochrome } \mathrm{C} \text { release }\end{array}$ & MTZ & $\begin{array}{l}\text { Wang et al., } \\
2009\end{array}$ \\
\hline $\begin{array}{l}\text { Wistar rat } \\
\text { tMCAO }\end{array}$ & $\begin{array}{c}\text { Decrease of infarct size } \\
\text { Reduction of AQP4 } \\
\text { expression } \\
\text { Reduction of brain } \\
\text { water content and } \\
\text { sodium accumulation }\end{array}$ & ATZ & Han et al., 2020 \\
\hline $\begin{array}{l}\text { Sprague } \\
\text { dawley rat } \\
\text { pMCAO }\end{array}$ & $\begin{array}{c}\text { Improvement of } \\
\text { neurological score } \\
\text { Reduction of infarct size }\end{array}$ & $\begin{array}{l}\text { CA-VII inhibition, } \\
\text { CA-IXXII inhibition } \\
\text { ATZ, CA-IXXII } \\
\text { inhibition }\end{array}$ & $\begin{array}{c}\text { Di Cesare } \\
\text { Mannelli et al., } \\
2016\end{array}$ \\
\hline $\begin{array}{l}\text { Rat } \\
\text { hippocampal } \\
\text { slices }\end{array}$ & $\begin{array}{l}\text { Inhibition of OGD } \\
\text { induced anoxic } \\
\text { depolarization }\end{array}$ & $\begin{array}{c}\text { ATZ, CA-IX } \\
\text { inhibition, CA-XII } \\
\text { inhibition }\end{array}$ & $\begin{array}{c}\text { Dettori et al., } \\
2021\end{array}$ \\
\hline $\begin{array}{l}\text { Wistar rats } \\
\text { pMCAO }\end{array}$ & $\begin{array}{c}\text { Reduction of infarct size } \\
\text { Improvement of } \\
\text { neurological score } \\
\text { Attenuation of microglia } \\
\text { activation }\end{array}$ & $\begin{array}{l}\text { ATZ, CA-IXJ-XII } \\
\text { inhibition }\end{array}$ & $\begin{array}{c}\text { Dettori et al., } \\
2021\end{array}$ \\
\hline
\end{tabular}

MTZ, Methazolamide; ATZ, Acetazolamide; HS, hemorrhagic stroke; p/Tmcao, permanent/transient middle cerebral artery occlusion; CA, carbonic anhydrase; AQP4, Aquaporin-4; OGD, oxygen glucose deprivation. was rescued by MTZ treatment. Similarly, OGD increased cytochrome $c$ release and apoptosis inducing factor (AIF) release from the mitochondria, as well as the activity of caspase-3 (Wang et al., 2009), and MTZ attenuated these effects (Wang et al., 2009), suggesting that MTZ does not only prevent necrosis, but also mitochondria-mediated apoptosis, induced by OGD. In the same study, primary cortical neurons exposed to OGD presented inflammasome activation, measured by the activation of caspase1 and release of IL- $1 \beta$. MTZ inhibited both IL- $1 \beta$ release as well as caspase- 1 activation in vitro (Wang et al., 2009). This finding supports the hypothesis that CAs may mediate both apoptotic and inflammatory mechanisms. In a mouse model of MCAO, MTZ-treated mice $(20 \mathrm{mg} / \mathrm{kg}$ ) had a smaller infarct size, improved neurological score, and decreased cytochrome c release and caspase- 3 activation, compared to non-treated mice (Wang et al., 2009). A more recent study performed in rats determined the effectiveness of ATZ alone, as well as in conjugation with head-down tilt, a way to physically promote CBF, in a transient MCAO rat model. The results indicated that ATZ was protective following transient MCAO, significantly decreasing infarct size (Han et al., 2020). Furthermore, ATZ reduced AQP4 expression, compared to rats with no treatment, suggesting a reduction in brain edema (Han et al., 2020). In a rat model of permanent MCAO, ATZ was used in comparison with selective inhibitors for CA-VII, CA-IX, and CA-XII to determine whether these

TABLE 2 | CA inhibition in models of HS.

\begin{tabular}{|c|c|c|c|}
\hline Model & Mechanism & $\begin{array}{c}\text { CA } \\
\text { Inhibitor/Isoform }\end{array}$ & References \\
\hline \multirow[t]{2}{*}{$\begin{array}{l}\text { Sprague- } \\
\text { dawley rats } \\
\text { intracaudate } \\
\text { blood injection }\end{array}$} & $\begin{array}{c}\text { Improvement of } \\
\text { neurological outcome } \\
\text { Reduction of } \\
\text { neuronal death }\end{array}$ & ATZ & $\begin{array}{c}\text { Guo et al., } \\
2012\end{array}$ \\
\hline & $\begin{array}{c}\text { Exacerbation of brain } \\
\text { water content } \\
\text { Increase } \\
\text { neurodegeneration }\end{array}$ & CA-I injection & $\begin{array}{c}\text { Guo et al., } \\
2012\end{array}$ \\
\hline \multirow[t]{2}{*}{$\begin{array}{l}\text { Mouse primary } \\
\text { cortical neurons }\end{array}$} & $\begin{array}{c}\text { Inhibition of } \\
\text { blood/hemoglobin } \\
\text { induced cell death }\end{array}$ & MTZ & Li et al., 2016 \\
\hline & $\begin{array}{l}\text { Inhibition of } \\
\text { blood/hemoglobin } \\
\text { induced ROS } \\
\text { production }\end{array}$ & & \\
\hline $\begin{array}{l}\text { C57BL/6J Mice } \\
\text { SAH }\end{array}$ & $\begin{array}{c}\text { Reduction in } \\
\text { caspase-3 activation } \\
\text { and cell death in } \\
\text { hippocampus/cortex } \\
\text { Improvement in } \\
\text { neurological outcome }\end{array}$ & MTZ & Li et al., 2016 \\
\hline $\begin{array}{l}\text { New Zealand } \\
\text { White Rabbits } \\
\text { SAH }\end{array}$ & $\begin{array}{c}\text { Reduction of } \\
\text { neurodegeneration/ } \\
\text { apoptosis in } \\
\text { hippocampus }\end{array}$ & Topiramate & $\begin{array}{c}\text { Seçkin et al., } \\
2009\end{array}$ \\
\hline
\end{tabular}

ATZ, acetazolamide; MTZ, methazolamide; CA-I, carbonic anhydrase-1; SAH, subarachnoid hemorrhage; ROS, reactive oxygen species. 
isoforms are involved in the pathology. Interestingly, the panCAI ATZ did not improve neurological score $24 \mathrm{~h}$ following occlusion, however, the CAI with selectivity for CA-VII, as well as the compound more selective for membrane isoforms CAIX and CA-XII, improved the neurological deficits observed in the occluded untreated rats. In the group treated with the CA-IX/CA XII potent and medium selective inhibitor, 6(benzyloxy)benzo[d] thiazole-2-sulfonamide (BBT), infarct size was significantly reduced, while no reduction was observed

TABLE 3 | CA inhibition in models of AD and CAA.

\begin{tabular}{|c|c|c|c|}
\hline Model & Mechanism & $\begin{array}{c}\text { CA } \\
\text { Inhibitor/Isoform }\end{array}$ & References \\
\hline hCMEC/D3 & $\begin{array}{l}\text { Inhibition of } A \beta \text { induced } \\
D N A \text { fragmentation } \\
\text { Inhibition } A \beta \text { induced of } \\
\text { cytochrome } c \text { release } \\
\text { Inhibition of } A \beta \text { induced } \\
\mathrm{H}_{2} \mathrm{O}_{2} \text { production } \\
\text { Inhibition of } A \beta \text { induced } \\
\text { caspase- } 9 \text { activity }\end{array}$ & MTZ, ATZ & $\begin{array}{l}\text { Fossati et al., } \\
\text { 2010; Solesio } \\
\text { et al., } 2018\end{array}$ \\
\hline $\begin{array}{l}\text { Human primary } \\
\text { brain SMC }\end{array}$ & $\begin{array}{l}\text { Inhibition of } A \beta \text { induced } \\
\text { DNA fragmentation } \\
\text { Inhibition } A \beta \text { induced of } \\
\text { cytochrome c release }\end{array}$ & MTZ & $\begin{array}{l}\text { Fossati et al., } \\
2010\end{array}$ \\
\hline $\begin{array}{l}\text { Normal Human } \\
\text { Astrocytes }\end{array}$ & $\begin{array}{l}\text { Inhibition of A } \beta \text { induced } \\
\text { DNA fragmentation }\end{array}$ & MTZ & $\begin{array}{l}\text { Fossati et al., } \\
\quad 2016\end{array}$ \\
\hline $\begin{array}{l}\text { Human Glioma } \\
\text { M059K }\end{array}$ & $\begin{array}{l}\text { Inhibition of } A \beta \text { induced } \\
\text { DNA fragmentation } \\
\text { Inhibition } A \beta \text { induced of } \\
\text { cytochrome } c \text { release } \\
\text { Inhibition of } A \beta \text { induced } \\
\mathrm{H}_{2} \mathrm{O}_{2} \text { production } \\
\text { Inhibition of } A \beta \text { induced } \\
\text { caspase- } 9 \text { activity }\end{array}$ & MTZ & $\begin{array}{c}\text { Fossati et al., } \\
2016\end{array}$ \\
\hline $\begin{array}{l}\text { Human } \\
\text { Neuroblastoma } \\
\text { (SHSY5Y) }\end{array}$ & $\begin{array}{l}\text { Inhibition of } A \beta \text { induced } \\
D N A \text { fragmentation } \\
\text { Inhibition } A \beta \text { induced of } \\
\text { cytochrome } c \text { release } \\
\text { Inhibition of } A \beta \text { induced } \\
\mathrm{H}_{2} \mathrm{O}_{2} \text { production } \\
\text { Inhibition of } A \beta \text { induced } \\
\text { caspase- } 9 \text { activity }\end{array}$ & MTZ, ATZ & $\begin{array}{l}\text { Fossati et al., } \\
\text { 2016; Solesio } \\
\text { et al., } 2018\end{array}$ \\
\hline & Activation of Nrf2 & MTZ & $\begin{array}{l}\text { Sotolongo } \\
\text { et al., } 2020\end{array}$ \\
\hline $\begin{array}{l}\text { Rat primary cortical } \\
\text { neurons }\end{array}$ & Activation of Nrf2 & MTZ & $\begin{array}{l}\text { Sotolongo } \\
\text { et al., } 2020\end{array}$ \\
\hline $\begin{array}{l}\text { C57BL/6 Mice A } \beta \\
\text { hippocampal } \\
\text { injection }\end{array}$ & $\begin{array}{l}\text { Inhibition of caspase-3 } \\
\text { activation } \\
\text { Increase of NeuN } \\
\text { expression in } \\
\text { hippocampus } \\
\text { Reduction of } \\
\text { caspase-3 activation in } \\
\text { reactive microglia }\end{array}$ & MTZ & $\begin{array}{l}\text { Fossati et al., } \\
2016\end{array}$ \\
\hline
\end{tabular}

hCMEC/D3, human cerebral microvasculature endothelial cells; $A \beta$, amyloid-beta; MTZ, methazolamide; ATZ, acetazolamide; SMC, smooth muscle cell; SHSY5Y, human neuroblastoma cells; MO59K, glioblastoma cell line; Nrf2, nuclear factor erythroid 2-related factor. in the CA-VII inhibitor group. However, rats treated with $50 \mathrm{mg} / \mathrm{kg}$ of ATZ also displayed diminished infarct volume. This study suggests that CA-IX and possibly CA-XII may exacerbate neuronal loss along with neurological and vascular deficits, following ischemic insult (Di Cesare Mannelli et al., 2016). Very recently, another study evaluated different CA-selective inhibitors, in both in vitro and in vivo models of IS (Dettori et al., 2021). This study analyzed a new generation of CAIs, which are lipophilic and selective for the hypoxia-associated (CA-IX and CA-XII) and cytosolic (CA-II and CA-I) isoforms. Importantly, ATZ was used as a reference compound at a much lower dose in this study $(4.4 \mathrm{mg} / \mathrm{kg})$. In vitro, the lipophilic CAIs and ATZ protected against OGD-induced anoxic depolarization, providing mechanistic information. In vivo, the CAIs reduced infarct volume, neurological deficits, neuronal damage and microglial activation (Dettori et al., 2021). This study also measured TNF$\alpha$ and Il-10 plasma levels, showing differences between the sham surgery and the occluded groups, without any affect in the treated groups, likely due to the short time window of treatment (24-h). As proposed in the discussion, it is possible that, with a longer treatment, CA inhibition may mediate inflammatory pathways (Bulli et al., 2021; Dettori et al., 2021). Indeed, CAs have been also associated with inflammatory pathologies, such as rheumatoid arthritis and cancer metastasis (Supuran, 2008; Alver et al., 2011; Liu et al., 2012). Overall, both MTZ and ATZ are protective in models of IS, however, the development of CAIX and potentially CA-XII inhibitors may be beneficial for the treatment of both neurological and vascular disorders, following IS. The protective mechanisms observed following CA inhibition in models of IS, summarized in Table 2, seem to be superior with compounds selective for membrane-bound isoforms CA-IX and CA-XII (Bulli et al., 2021).

\section{Carbonic Anhydrase Inhibition in Models of Hemorrhagic Stroke}

The protective mechanisms of CA inhibition in models of HS are summarized in Table 2. Inhibition of CA reduced brain injury after ICH in Sprague-Dawley rats (Guo et al., 2012). This study focused on CA-I, which is highly expressed in red blood cells. Upon intracaudate injection of blood, CA-I levels were increased in the ipsilateral basal ganglia, for as long as 3 days postinjection. Moreover, following intracaudate injection of CA-I, increased brain water content, microglial activation and neuronal cell death were detected, suggesting that CA-I expression may contribute to cerebral edema and neuroinflammation. ATZtreated rats exhibited reduced perihematomal edema, as well as sodium accumulation, together with decreased neuronal deficits (Guo et al., 2012). However, the cellular mechanisms responsible for the effects of CA-I on BBB integrity require further investigation. Lately, the scientific community is beginning to hypothesize that CA-I, in both the retina and brain, contributes to vascular permeability, suggesting that specific inhibitors of CA-I could be beneficial to minimize NVU dysfunction, and thus neuroinflammation around the barrier (Gao et al., 2007). Furtherly, in a SAH mouse model, mice treated with the pan-CAI, MTZ, had decreased caspase-3 activation and 
apoptosis in the hippocampus and cortex, compared to the non-treated group, ameliorating neurological deficits (Li et al., 2016). In primary cortical neurons, MTZ reduced hemoglobin and blood induced cell death along with production of ROS (Li et al., 2016). Topiramate, another CAI active on multiple $\mathrm{CA}$ enzymes, including $\mathrm{CA}-\mathrm{V}$, reduced $\mathrm{SAH}$ injury in rabbits (Seçkin et al., 2009).

\section{Carbonic Anhydrase Inhibition in Models of Alzheimer's Disease and Cerebral Amyloid Angiopathy}

Recently, the effects of CA inhibition on mitochondrial and neurovascular cell function have been tested in models of amyloidosis (Table 3). In $\mathrm{AD}$ and $\mathrm{CAA}, \mathrm{A} \beta$ toxic aggregates accumulate around and within the cerebral vessel walls, as well as in parenchymal plaques in specific brain regions, such as the hippocampus and cortex (Ghiso et al., 2014; Cortes-Canteli and Iadecola, 2020). Our lab has shown that $\mathrm{A} \beta$ oligomers and protofibrils induce cytochrome $\mathrm{c}$ release from the mitochondria in multiple cell types of the NVU, including ECs and SMCs, neurons and glial cells, leading to caspase activation and cell death (Fossati et al., 2010, 2012a,b, 2016; Parodi-Rullán et al., 2020). In all of these neurovascular cell types, MTZ reduced mitochondrial mediated cell death triggered by $\mathrm{A} \beta$ (Fossati et al., 2010, 2016). Moreover, MTZ attenuated caspase-3 and caspase9 activation in ECs, neuronal and glial cells in vitro, as well as caspase-3 activation in vivo (Fossati et al., 2016; Solesio et al., 2018). In an in vivo study, $A \beta$ was injected into the hippocampus of wild-type mice, in the presence or absence of a previous intraperitoneal MTZ injection. Interestingly, MTZ treatment attenuated the activation of caspase- 3 in microglia and increased the amount of $\mathrm{NeuN}$ positive neurons within the hippocampus, indicating that MTZ treatment had a protective effect against neurodegeneration following $A \beta$-injection (Fossati et al., 2016). To elucidate the specific mechanisms responsible for these protective effects, our group showed that $\mathrm{A} \beta$-induced mitochondrial dysfunction, mitochondrial membrane depolarization, cytochrome $\mathrm{C}$ release, and $\mathrm{H}_{2} \mathrm{O}_{2}$ production were attenuated in neuronal and ECs, not only by MTZ, but also by ATZ, which was effective at lower concentrations (Solesio et al., 2018). Moreover, both ATZ and MTZ inhibited caspase- 9 activation caused by A $\beta$ in cerebrovascular EC, and the resulting apoptosis (Solesio et al., 2018). MTZ has been also observed to increase the activation of nuclear factor-related factor 2 (Nrf2), in models of high-altitude sickness and more interestingly, in human neuroblastoma cells and primary cortical neurons challenged with A $\beta$ in vitro (Lu et al., 2020; Sotolongo et al., 2020). Nrf2-activation by MTZ increased the activity of antioxidant enzymes, such as superoxide dismutase- 1 and heme-oxygenase-1, pointing to the potential downstream effects of MTZ (Sotolongo et al., 2020). These studies support the hypothesis that CA inhibition is protective to multiple cell types of the NVU, in models of amyloidosis, and highlight the necessity to test

TABLE 4 | CA isoforms in CNS and cerebrovascular pathology.

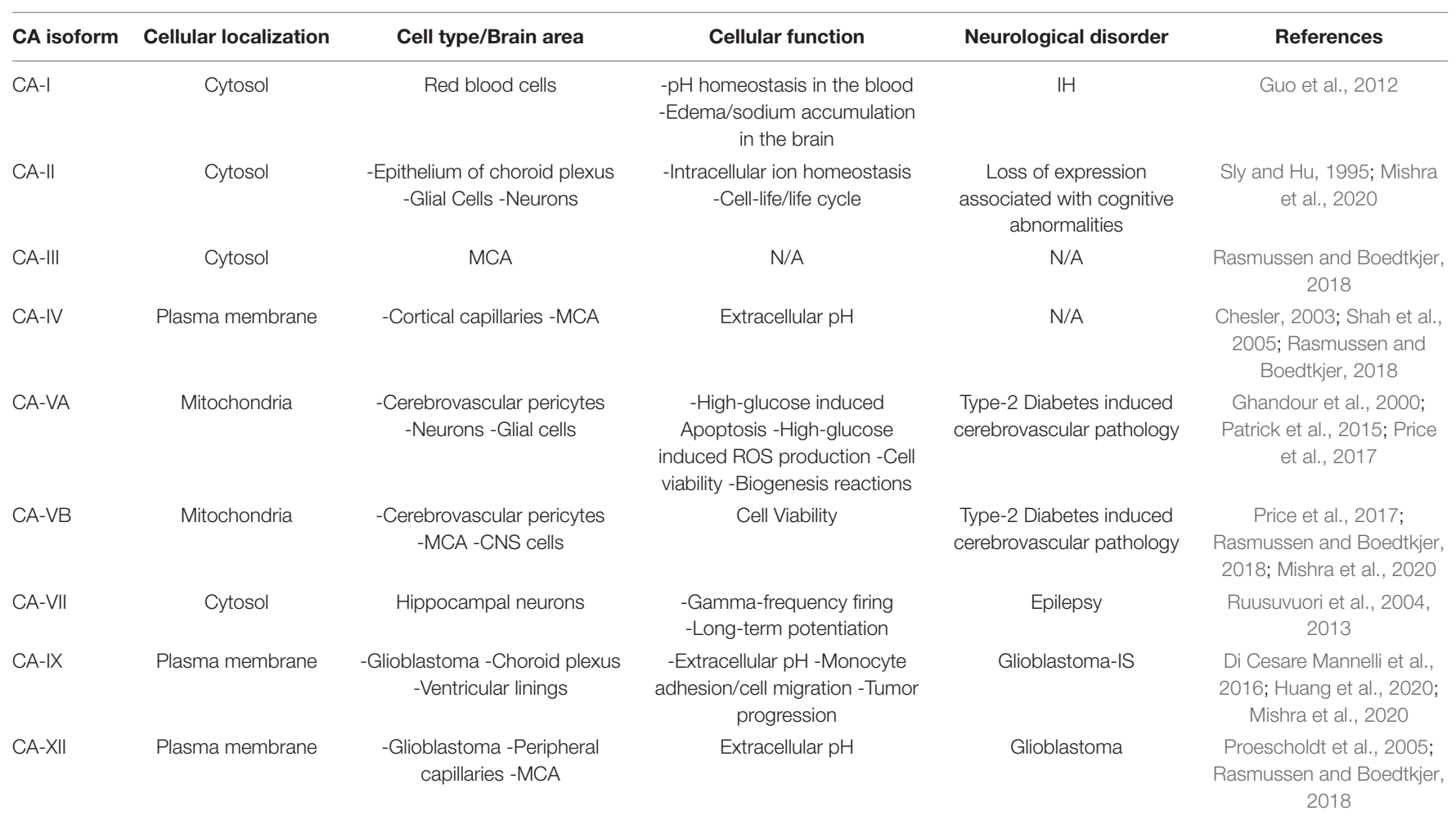

CA, carbonic anhydrase; MCA, middle cerebral artery; IH, intracerebral hemorrhage; IS, ischemic stroke. 
these and/or isoform-specific compounds in clinical trials for $\mathrm{AD}$ and CAA. New studies currently performed in our lab are also confirming the positive effects of CAIs on cognitive performance in mouse models of amyloidosis (Angiulli et al., 2018). Additional studies are in process to investigate chronic treatments with pan-CAIs in multiple models of CAA and AD, in parallel with the assessment of specific isoform inhibitors, to further elucidate the role of different CA isoforms in $\mathrm{AD}$ and CAA pathology.

Interestingly, although CAIs are proving to be beneficial in preventing $\mathrm{CAA}$ and $\mathrm{AD}$ pathology, CA activators have also showed beneficial effects for memory retention in acute models (Ilies et al., 2002; Canto de Souza et al., 2017; Sanku et al., 2018; Provensi et al., 2019; Blandina et al., 2020; Schmidt et al., 2020). These findings point to a relevant role of CA enzymes in the modulation of multiple pathways in contextual fear memory extinction, neurodegenerative and neurovascular pathology. They also highlight the need for a careful and specific modulation of CA enzyme's activity, and for a further understanding of the effects of each isoform in different brain areas, cell types, and pathological conditions.

\section{Carbonic Anhydrase Inhibition in Models of Diabetes-Induced Cerebrovascular Pathology}

Some studies have also explored the specific inhibition of the mitochondrial isoforms $\mathrm{CA}-\mathrm{VA}$ and $\mathrm{CA}-\mathrm{VB}$, which recently gained interest for their role in the prevention of cerebrovascular pathology, in different models of diabetes (Price et al., 2012, 2017; Shah et al., 2013a), which contributes to AD and stroke pathogenesis (Kuźma et al., 2018; Cortes-Canteli and Iadecola, 2020; Freitas-Andrade et al., 2020; Zlokovic et al., 2020). In a streptozotocin induced diabetic CD-1 mouse model it was reported that topiramate treatment for 3 weeks increased the levels of glutathione and reduced oxidative stress in the brain. It was also observed that diabetes-induced loss of cerebral pericytes was attenuated by topiramate (Price et al., 2012). The same group confirmed these mechanisms in the brains of $\mathrm{CA}-\mathrm{V}$ double $\mathrm{KO}$ mice, where increased levels of glutathione and decreased oxidative stress was observed compared to wildtype (Price et al., 2012). Hyperglycemia-treated cerebrovascular pericytes increased ROS production, as well as the rate of

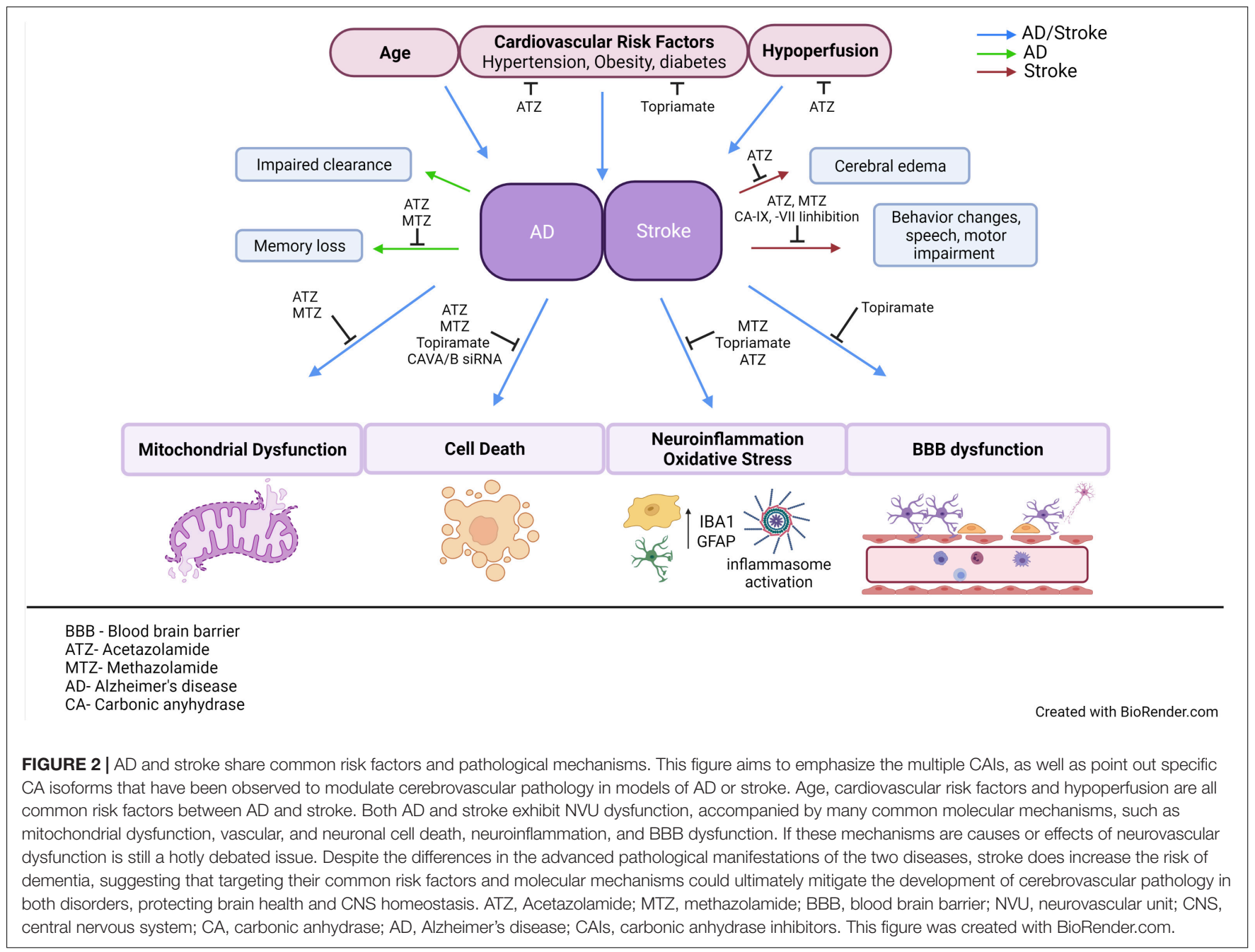


mitochondrial respiration. The inhibition of CA (particularly CA-V), with topiramate, reduced ROS production (Shah et al., 2013a). Although topiramate has a high inhibitory activity on the CA-V isoforms, it also has affinity for the other isoforms, as well as multiple off-target effects in the brain, as shown by studies that analyzed topiramate's functions on GABA and glutamate receptors (Johnson, 2005; Mao et al., 2015). Ideally, more specific inhibitors should be developed to further investigate the functions of CA-VA/B. The same group used a plasmid to overexpress CA-VA in cerebral pericytes exposed to high-glucose to confirm the hypothesized molecular mechanisms involving CA-VA, such as ROS production and cell death, observing that topiramate was protective against these mechanisms (Patrick et al., 2015). As a proof of concept, the same group genetically knocked down CA-VA and CA-VB in cerebral pericytes (Price et al., 2017). CA-VA and CA-VB knockdown improved cell viability, compared to the control, when exposed to hyperglycemia, although the specific knockdown of CA-VA was even more effective than CA-VB knockdown in decreasing ROS production and apoptosis, in a hyperglycemic environment (Price et al., 2017). These studies reveal potential differences between CA-VA and CA-VB function in brain pericytes, which need further investigation. In a streptozotocin induced diabetic mouse model, cerebrovascular pathology was also characterized using electron microscopy. The breakdown of the BBB and its dysfunction was attenuated by topiramate treatment in vivo (Salameh et al., 2016). More recently, a study using a high-fatinduced diabetes mouse model, focused on the disruption of the hippocampal BBB. BBB tight junction proteins, such as ZO- 1 and claudin-12, were reduced with a high-fat diet, while topiramate treatment increased their expression, along with the attenuation of oxidative stress (Salameh et al., 2019).

\section{CONCLUSION}

The NVU is an important functional structure of the CNS, and its failure participates in the development of $\mathrm{AD}$, vascular dementias, and exacerbates stroke outcomes. Multiple pathological and cellular mechanisms leading to NVU pathology need clarification, and new therapeutic strategies should be further investigated and developed. As scientific techniques improve, the ability to understand the functions of this unit increases. Recent studies support that CA inhibition is protective to the NVU, and the role of these enzymes should be further investigated. Table 4 emphasizes the CA isoforms that have been discussed throughout the review, their cellular localizations, their association with specific neurological disorders, and their

\section{REFERENCES}

Akocak, S., Alam, M. R., Shabana, A. M., Sanku, R. K., Vullo, D., Thompson, H., et al. (2016). PEGylated Bis-Sulfonamide Carbonic Anhydrase Inhibitors Can Efficiently Control the Growth of Several Carbonic Anhydrase IX-Expressing Carcinomas. J. Med. Chem. 59, 5077-5088. doi: 10.1021/acs.jmedchem. 6b00492 expression in neurovascular cells. Clarifying how the cells of the NVU interact with each other, as well as the roles of CAs within each cell type, is critical for targeting cerebrovascular pathology in IS, AD, as well as other neurogenerative diseases. The pan-CAIs MTZ and ATZ, as well as topiramate, have shown protective effects in models of stroke, cerebrovascular pathology, type II diabetes, and AD, summarized in Figure 2. Although these compounds are FDA-approved, facilitating translation to clinical trials, these CAIs are not specific drugs. Isoform-specific CAIs are of increasing interest, as 15 isoforms with different functions and localizations have been identified in humans. Further preclinical and clinical studies to assess the efficacy of $\mathrm{CA}$ inhibition in $\mathrm{AD}$ as well as IS are essential. To confirm the role of specific CA isoforms as pharmacological targets, genetic studies, such as isoform KO and knock in in different NVU cell types, would be beneficial. Overall, the studies discussed above provide evidence for CAs as important potential mediators and targets in neurovascular pathology for $\mathrm{AD}$, stroke and related cerebrovascular disorders.

\section{AUTHOR CONTRIBUTIONS}

NL and SF designed and conceptualized the review. NL wrote the review draft and did the literature search. SF critically revised, edited the manuscript, provided relevant insights, additional literature search, and acquired funding. EC and MI revised the manuscript and provided additional literature search. All authors contributed to the article and approved the submitted version.

\section{FUNDING}

This work was supported by NIH R01NS104127 and R01AG062572 grants, the Edward N. and Della L. Thome Memorial Foundation Awards Program in Alzheimer's Disease Drug Discovery Research, the Alzheimer's Association (AARG), the Pennsylvania Department of Heath Collaborative Research on Alzheimer's Disease (PA Cure) Grant, awarded to SF, and by the Karen Toffler Charitable Trust, and the Lemole Center for Integrated Lymphatics research.

\section{ACKNOWLEDGMENTS}

We thank Ashley Carey for conceptualizing and drawing Figure 1 of the review. We also acknowledge that Figure 2 was created using BioRender.com. Supuran., and C. Cappasso. (London: Future Science Ltd). 34-51. doi: 10.4155/ fseb2013.13.22

Aldea, R., Weller, R. O., Wilcock, D. M., Carare, R. O., and Richardson, G. (2019). Cerebrovascular Smooth Muscle Cells as the Drivers of Intramural Periarterial Drainage of the Brain. Front. Aging Neurosci. 11:1. 
Alluri, H., Stagg, H. W., Wilson, R. L., Clayton, R. P., Sawant, D. A., Koneru, M., et al. (2014). Reactive oxygen species-caspase-3 relationship in mediating blood-brain barrier endothelial cell hyperpermeability following oxygenglucose deprivation and reoxygenation. Microcirculation 21, 187-195.

Alterio, V., Di Fiore, A., D’ambrosio, K., Supuran, C. T., and De Simone, G. (2012). Multiple binding modes of inhibitors to carbonic anhydrases: how to design specific drugs targeting 15 different isoforms? Chem. Rev. 112, 4421-4468. doi: $10.1021 / \mathrm{cr} 200176 \mathrm{r}$

Alterio, V., Hilvo, M., Di Fiore, A., Supuran, C. T., Pan, P., Parkkila, S., et al. (2009). Crystal structure of the catalytic domain of the tumor-associated human carbonic anhydrase IX. Proc. Natl. Acad. Sci. U. S. A. 106, 16233-16238. doi: 10.1073/pnas.0908301106

Alver, A., Şentürk, A., Çakirbay, H., Menteşe, A., Gökmen, F., Keha, E. E., et al. (2011). Carbonic anhydrase II autoantibody and oxidative stress in rheumatoid arthritis. Clin. Biochem. 44, 1385-1389. doi: 10.1016/j.clinbiochem.2011.09.014

Andreone, B. J., Lacoste, B., and Gu, C. (2015). Neuronal and vascular interactions. Annu. Rev. Neurosci. 38, 25-46. doi: 10.1146/annurev-neuro-071714-033835

Andring, J. T., Fouch, M., Akocak, S., Angeli, A., Supuran, C. T., Ilies, M. A., et al. (2020). Structural Basis of Nanomolar Inhibition of Tumor-Associated Carbonic Anhydrase IX: X-Ray Crystallographic and Inhibition Study of Lipophilic Inhibitors with Acetazolamide Backbone. J. Med. Chem. 63, 1306413075. doi: 10.1021/acs.jmedchem.0c01390

Angeli, A., Carta, F., Nocentini, A., Winum, J. Y., Zalubovskis, R., Akdemir, A., et al. (2020). Carbonic Anhydrase Inhibitors Targeting Metabolism and Tumor Microenvironment. Metabolites 10:412. doi: 10.3390/metabo10100412

Angeli, A., Vaiano, F., Mari, F., Bertol, E., and Supuran, C. T. (2017). Psychoactive substances belonging to the amphetamine class potently activate brain carbonic anhydrase isoforms VA, VB, VII, and XII. J. Enzyme Inhib. Med. Chem. 32, 1253-1259. doi: 10.1080/14756366.2017.1375485

Angiulli, F., Solesio, M. E., Debure, L., Cejudo, J. R., Wisniewski, T., and Fossati, S. (2018). P3-464: carbonic anhydrase inhibitors ameliorate neurovascular dysfunction in a mouse model of cerebral amyloid angiopathy. Alzheimers Dement. 14, 1296-1296. doi: 10.1016/j.jalz.2018.06.1828

Aspatwar, A., Tolvanen, M. E., Ortutay, C., and Parkkila, S. (2014). Carbonic anhydrase related proteins: molecular biology and evolution. Subcell. Biochem. 75, 135-156. doi: 10.1007/978-94-007-7359-2 8

Austin, S. A., Santhanam, A. V., Hinton, D. J., Choi, D. S., and Katusic, Z. S. (2013). Endothelial nitric oxide deficiency promotes Alzheimer's disease pathology. J. Neurochem. 127, 691-700. doi: 10.1111/jnc.12334

Badimon, A., Strasburger, H. J., Ayata, P., Chen, X., Nair, A., Ikegami, A., et al. (2020). Negative feedback control of neuronal activity by microglia. Nature 586, 417-423. doi: 10.1038/s41586-020-2777-8

Bains, J. S., and Shaw, C. A. (1997). Neurodegenerative disorders in humans: the role of glutathione in oxidative stress-mediated neuronal death. Brain Res.Rev. 25, 335-358. doi: 10.1016/S0165-0173(97)00045-3

Bertini, I., and Luchinat, C. (1983). Cobalt(II) as a probe of the structure and function of carbonic anhydrase. Accounts Chem. Res. 16, 272-279. doi: 10.1021/ ar00092a002

Biernaskie, J., Corbett, D., Peeling, J., Wells, J., and Lei, H. (2001). A serial MR study of cerebral blood flow changes and lesion development following endothelin-1induced ischemia in rats. Magn. Reson Med. 46, 827-830. doi: 10.1002/mrm. 1263

Blandina, P., Provensi, G., Passsani, M. B., Capasso, C., and Supuran, C. T. (2020). Carbonic anhydrase modulation of emotional memory. Implications for the treatment of cognitive disorders. J. Enzyme Inhib. Med. Chem. 35, 1206-1214. doi: 10.1080/14756366.2020.1766455

Boespflug, E. L., and Iliff, J. J. (2018). The Emerging Relationship Between Interstitial Fluid-Cerebrospinal Fluid Exchange, Amyloid-beta, and Sleep. Biol. Psychiatry 83, 328-336. doi: 10.1016/j.biopsych.2017.11.031

Boland, B., Yu, W. H., Corti, O., Mollereau, B., Henriques, A., Bezard, E., et al. (2018). Promoting the clearance of neurotoxic proteins in neurodegenerative disorders of ageing. Nat. Rev. Drug Discov. 17, 660-688. doi: 10.1038/nrd.20 18.109

Boriack-Sjodin, P. A., Heck, R. W., Laipis, P. J., Silverman, D. N., and Christianson, D. W. (1995). Structure determination of murine mitochondrial carbonic anhydrase $\mathrm{V}$ at 2.45-A resolution: implications for catalytic proton transfer and inhibitor design. Proc. Natl. Acad. Sci. U. S. A. 92, 10949-10953. doi: 10.1073/pnas.92.24.10949
Boyd, N. H., Walker, K., Fried, J., Hackney, J. R., Mcdonald, P. C., Benavides, G. A., et al. (2017). Addition of carbonic anhydrase 9 inhibitor SLC-0111 to temozolomide treatment delays glioblastoma growth in vivo. JCI Insight 2:e92928. doi: 10.1172/jci.insight.92928

Bradwell, A. R., Wright, A. D., Winterborn, M., and Imray, C. (1992). Acetazolamide and high altitude diseases. Int. J. Sports Med. 13, S63-S64. doi: 10.1055/s-2007-1024597

Braun, M., and Iliff, J. J. (2020). The impact of neurovascular, blood-brain barrier, and glymphatic dysfunction in neurodegenerative and metabolic diseases. Int. Rev. Neurobiol. 154, 413-436. doi: 10.1016/bs.irn.2020.02.006

Bulli, I., Dettori, I., Coppi, E., Cherchi, F., Venturini, M., Di Cesare Mannelli, L., et al. (2021). Role of Carbonic Anhydrase in Cerebral Ischemia and Carbonic Anhydrase Inhibitors as Putative Protective Agents. Int. J. Mol. Sci. 22:5029. doi: 10.3390/ijms22095029

Canepa, E., and Fossati, S. (2020). Impact of Tau on Neurovascular Pathology in Alzheimer's Disease. Front. Neurol. 11:573324. doi: 10.3389/fneur.2020.573324

Canto de Souza, L., Provensi, G., Vullo, D., Carta, F., Scozzafava, A., et al. (2017). Carbonic anhydrase activation enhances object recognition memory in mice through phosphorylation of the extracellular signal-regulated kinase in the cortex and the hippocampus. Neuropharmacology 118, 148-156. doi: 10.1016/ j.neuropharm.2017.03.009

Carare, R. O., Aldea, R., Agarwal, N., Bacskai, B. J., Bechman, I., Boche, D., et al. (2020). Clearance of interstitial fluid (ISF) and CSF (CLIC) group-part of Vascular Professional Interest Area (PIA): cerebrovascular disease and the failure of elimination of Amyloid- $\beta$ from the brain and retina with age and Alzheimer's disease-Opportunities for Therapy. Alzheimers Dement. 12:e12053. doi: $10.1002 / \mathrm{dad} 2.12053$

Carare, R. O., Bernardes-Silva, M., Newman, T. A., Page, A. M., Nicoll, J. A., Perry, V. H., et al. (2008). Solutes, but not cells, drain from the brain parenchyma along basement membranes of capillaries and arteries: significance for cerebral amyloid angiopathy and neuroimmunology. Neuropathol. Appl. Neurobiol. 34, 131-144. doi: 10.1111/j.1365-2990.2007.00926.x

Carcel-Marquez, J., Cullell, N., Muino, E., Gallego-Fabrega, C., Lledos, M., Ibanez, L., et al. (2021). Causal Effect of MMP-1 (Matrix Metalloproteinase-1), MMP8, and MMP-12 Levels on Ischemic Stroke: a Mendelian Randomization Study. Stroke 52, e316-e320. doi: 10.1161/STROKEAHA.120.033041

Castillo-Carranza, D. L., Nilson, A. N., Van Skike, C. E., Jahrling, J. B., Patel, K., Garach, P., et al. (2017). Cerebral Microvascular Accumulation of Tau Oligomers in Alzheimer's Disease and Related Tauopathies. Aging Dis. 8, 257266. doi: 10.14336/AD.2017.0112

Chesler, M. (2003). Regulation and modulation of pH in the brain. Physiol. Rev. 83, 1183-1221. doi: 10.1152/physrev.00010.2003

Corraini, P., Henderson, V. W., Ording, A. G., Pedersen, L., Horváth-Puhó, E., and Sørensen, H. T. (2017). Long-Term Risk of Dementia Among Survivors of Ischemic or Hemorrhagic Stroke. Stroke 48, 180-186. doi: 10.1161/ STROKEAHA.116.015242

Cortes-Canteli, M., and Iadecola, C. (2020). Alzheimer's Disease and Vascular Aging: JACC Focus Seminar. J. Am. Coll. Cardiol. 75, 942-951. doi: 10.1016/ j.jacc.2019.10.062

Cruz Hernández, J. C., Bracko, O., Kersbergen, C. J., Muse, V., Haft-Javaherian, M., Berg, M., et al. (2019). Neutrophil adhesion in brain capillaries reduces cortical blood flow and impairs memory function in Alzheimer's disease mouse models. Nat. Neurosci. 22, 413-420. doi: 10.1038/s41593-018-0329-4

Da Mesquita, S., Louveau, A., Vaccari, A., Smirnov, I., Cornelison, R. C., and Kingsmore, K. M. (2018). Functional aspects of meningeal lymphatics in ageing and Alzheimer's disease. Nature 560, 185-191. doi: 10.1038/s41586-018-0368-8

Day, R. J., Mason, M. J., Thomas, C., Poon, W. W., and Rohn, T. T. (2015). Caspase-Cleaved Tau Co-Localizes with Early Tangle Markers in the Human Vascular Dementia Brain. PLoS One 10:e0132637. doi: 10.1371/journal.pone.01 32637

de Bruijn, R. F., and Ikram, M. A. (2014). Cardiovascular risk factors and future risk of Alzheimer's disease. BMC Med. 12:130. doi: 10.1186/s12916-014-0130-5

De Simone, G., and Supuran, C. T. (2007). Antiobesity carbonic anhydrase inhibitors. Curr. Top. Med. Chem. 7, 879-884. doi: $10.2174 / 156802607780636762$

Dejakaisaya, H., Kwan, P., and Jones, N. C. (2021). Astrocyte and glutamate involvement in the pathogenesis of epilepsy in Alzheimer's disease. Epilepsia 62, 1485-1493. doi: 10.1111/epi.16918 
Demandt, J. A. F., Dubois, L. J., Van Kuijk, K., Zat́ovičová, M., Jin, H., Parkkila, S., et al. (2021). The hypoxia-sensor carbonic anhydrase IX affects macrophage metabolism, but is not a suitable biomarker for human cardiovascular disease. Sci. Rep. 11:425. doi: 10.1038/s41598-020-79978-5

Dettori, I., Fusco, I., Bulli, I., Gaviano, L., Coppi, E., Cherchi, F., et al. (2021). Protective effects of carbonic anhydrase inhibition in brain ischaemia. J. Enzyme Inhib. Med. Chem. 36, 964-976. doi: 10.1080/14756366.2021.1907575

Di Cesare Mannelli, L., Micheli, L., Carta, F., Cozzi, A., Ghelardini, C., and Supuran, C. T. (2016). Carbonic anhydrase inhibition for the management of cerebral ischemia: in vivo evaluation of sulfonamide and coumarin inhibitors. J. Enzyme Inhib. Med. Chem. 31, 894-899. doi: 10.3109/14756366.2015.1113407

Draghici, B., Vullo, D., Akocak, S., Walker, E. A., Supuran, C. T., and Ilies, M. A. (2014). Ethylene bis-imidazoles are highly potent and selective activators for isozymes VA and VII of carbonic anhydrase, with a potential nootropic effect. Chem. Commun. 50, 5980-5983. doi: 10.1039/C4CC02346C

DuBose, T. D. Jr. (1984). Carbonic anhydrase-dependent bicarbonate transport in the kidney. Ann. N. Y. Acad. Sci. 429, 528-537. doi: 10.1111/j.1749-6632.1984. tb12382.x

Eldahshan, W., Fagan, S. C., and Ergul, A. (2019). Inflammation within the neurovascular unit: focus on microglia for stroke injury and recovery. Pharmacol. Res. 147:104349. doi: 10.1016/j.phrs.2019.104349

Engelhardt, S., Al-Ahmad, A. J., Gassmann, M., and Ogunshola, O. O. (2014). Hypoxia selectively disrupts brain microvascular endothelial tight junction complexes through a hypoxia-inducible factor-1 (HIF-1) dependent mechanism. J. Cell. Physiol. 229, 1096-1105. doi: 10.1002/jcp.24544

Faraco, G., Fossati, S., Bianchi, M. E., Patrone, M., Pedrazzi, M., Sparatore, B., et al. (2007). High mobility group box 1 protein is released by neural cells upon different stresses and worsens ischemic neurodegeneration in vitro and in vivo. J. Neurochem. 103, 590-603. doi: 10.1111/j.1471-4159.2007.04788.x

Ferrero, J., Williams, L., Stella, H., Leitermann, K., Mikulskis, A., O'gorman, J., et al. (2016). First-in-human, double-blind, placebo-controlled, single-dose escalation study of aducanumab (BIIB037) in mild-to-moderate Alzheimer's disease. Alzheimers Dement. 2, 169-176. doi: 10.1016/j.trci.2016.06.002

Fossati, S., Cam, J., Meyerson, J., Mezhericher, E., Romero, I. A., Couraud, P. O., et al. (2010). Differential activation of mitochondrial apoptotic pathways by vasculotropic amyloid-beta variants in cells composing the cerebral vessel walls. FASEB J. 24, 229-241. doi: 10.1096/fj.09-139584

Fossati, S., Ghiso, J., and Rostagno, A. (2012a). Insights into caspase-mediated apoptotic pathways induced by amyloid-beta in cerebral microvascular endothelial cells. Neurodegener. Dis. 10, 324-328. doi: 10.1159/000332821

Fossati, S., Ghiso, J., and Rostagno, A. (2012b). TRAIL death receptors DR4 and DR5 mediate cerebral microvascular endothelial cell apoptosis induced by oligomeric Alzheimer's A $\beta$. Cell Death Dis. 3, e321. doi: 10.1038/cddis.2012.55

Fossati, S., Giannoni, P., Solesio, M. E., Cocklin, S. L., Cabrera, E., Ghiso, J., et al. (2016). The carbonic anhydrase inhibitor methazolamide prevents amyloid beta-induced mitochondrial dysfunction and caspase activation protecting neuronal and glial cells in vitro and in the mouse brain. Neurobiol. Dis. 86, 29-40. doi: 10.1016/j.nbd.2015.11.006

Freitas-Andrade, M., Raman-Nair, J., and Lacoste, B. (2020). Structural and Functional Remodeling of the Brain Vasculature Following Stroke. Front. Physiol. 11:948. doi: 10.3389/fphys.2020.00948

Fujimura, M., Gasche, Y., Morita-Fujimura, Y., Massengale, J., Kawase, M., and Chan, P. H. (1999). Early appearance of activated matrix metalloproteinase-9 and blood-brain barrier disruption in mice after focal cerebral ischemia and reperfusion. Brain Res. 842, 92-100. doi: 10.1016/S0006-8993(99)01843-0

Gao, B. B., Clermont, A., Rook, S., Fonda, S. J., Srinivasan, V. J., Wojtkowski, M., et al. (2007). Extracellular carbonic anhydrase mediates hemorrhagic retinal and cerebral vascular permeability through prekallikrein activation. Nat. Med. 13, 181-188. doi: $10.1038 / \mathrm{nm} 1534$

Gervois, P., and Lambrichts, I. (2019). The Emerging Role of Triggering Receptor Expressed on Myeloid Cells 2 as a Target for Immunomodulation in Ischemic Stroke. Front. Immunol. 10:1668. doi: 10.3389/fimmu.2019.01668

Ghandour, M. S., Langley, O. K., Zhu, X. L., Waheed, A., and Sly, W. S. (1992). Carbonic anhydrase IV on brain capillary endothelial cells: a marker associated with the blood-brain barrier. Proc. Natl. Acad. Sci. U. S. A. 89, 6823-6827. doi: 10.1073 /pnas.89.15.6823

Ghandour, M. S., Parkkila, A. K., Parkkila, S., Waheed, A., and Sly, W. S. (2000). Mitochondrial carbonic anhydrase in the nervous system: expression in neuronal and glial cells. J. Neurochem. 75, 2212-2220. doi: 10.1046/j.14714159.2000.0752212.x

Ghiso, J., Fossati, S., and Rostagno, A. (2014). Amyloidosis associated with cerebral amyloid angiopathy: cell signaling pathways elicited in cerebral endothelial cells. J. Alzheimers Dis. 42, S167-S176. doi: 10.3233/JAD- 140027

Girouard, H., and Iadecola, C. (2006). Neurovascular coupling in the normal brain and in hypertension, stroke, and Alzheimer disease. J. Appl. Physiol. 100, 328-335. doi: 10.1152/japplphysiol.00966.2005

Gonul, E., Duz, B., Kahraman, S., Kayali, H., Kubar, A., and Timurkaynak, E. (2002). Early pericyte response to brain hypoxia in cats: an ultrastructural study. Microvasc. Res. 64, 116-119. doi: 10.1006/mvre.2002.2413

Grossmann, W. M., and Koeberle, B. (2000). The dose-response relationship of acetazolamide on the cerebral blood flow in normal subjects. Cerebrovasc. Dis. 10, 65-69. doi: 10.1159/000016027

Guo, F., Hua, Y., Wang, J., Keep, R. F., and Xi, G. (2012). Inhibition of carbonic anhydrase reduces brain injury after intracerebral hemorrhage. Transl. Stroke Res. 3, 130-137. doi: 10.1007/s12975-011-0106-0

Guo, J., Krause, D. N., Horne, J., Weiss, J. H., Li, X., and Duckles, S. P. (2010). Estrogen-receptor-mediated protection of cerebral endothelial cell viability and mitochondrial function after ischemic insult in vitro. J. Cereb. Blood Flow Metab. 30, 545-554. doi: 10.1038/jcbfm.2009.226

Güzel, O., Innocenti, A., Scozzafava, A., Salman, A., and Supuran, C. T. (2009). Carbonic anhydrase inhibitors. Phenacetyl-, pyridylacetyl- and thienylacetylsubstituted aromatic sulfonamides act as potent and selective isoform VII inhibitors. Bioorg. Med. Chem. Lett. 19, 3170-3173. doi: 10.1016/j.bmcl.2009. 04.123

Haapasalo, J., Nordfors, K., Haapasalo, H., and Parkkila, S. (2020). The Expression of Carbonic Anhydrases II, IX and XII in Brain Tumors. Cancers 12:1723. doi: $10.3390 /$ cancers 12071723

Hachinski, V., Einhaupl, K., Ganten, D., Alladi, S., Brayne, C., Stephan, B. C. M., et al. (2019). Preventing dementia by preventing stroke: the Berlin Manifesto. Alzheimers Dement. 15, 961-984. doi: 10.1016/j.jalz.2019.06.001

Hall, C. N., Reynell, C., Gesslein, B., Hamilton, N. B., Mishra, A., Sutherland, B. A., et al. (2014). Capillary pericytes regulate cerebral blood flow in health and disease. Nature 508, 55-60. doi: 10.1038/nature13165

Han, M., Kwon, I., Ha, J., Kim, J., Cha, M. J., Kim, Y. D., et al. (2020). Collateral augmentation treatment with a combination of acetazolamide and head-down tilt in a rat ischemic stroke model. J. Clin. Neurosci. 73, 252-258. doi: 10.1016/ j.jocn.2020.01.079

Hernandez-Guillamon, M., Mawhirt, S., Fossati, S., Blais, S., Pares, M., Penalba, A., et al. (2010). Matrix metalloproteinase 2 (MMP-2) degrades soluble vasculotropic amyloid-beta E22Q and L34V mutants, delaying their toxicity for human brain microvascular endothelial cells. J. Biol. Chem. 285, 27144-27158. doi: 10.1074/jbc.M110.135228

Hilvo, M., Baranauskiene, L., Salzano, A. M., Scaloni, A., Matulis, D., Innocenti, A., et al. (2008). Biochemical characterization of CA IX, one of the most active carbonic anhydrase isozymes. J. Biol. Chem. 283, 27799-27809. doi: 10.1074/ jbc.M800938200

Hong, J. H., Muhammad, E., Zheng, C., Hershkovitz, E., Alkrinawi, S., Loewenthal, N., et al. (2015). Essential role of carbonic anhydrase XII in secretory gland fluid and $\mathrm{HCO} 3(-)$ secretion revealed by disease causing human mutation. J. Physiol. 593, 5299-5312. doi: 10.1113/JP271378

Howarth, C., Sutherland, B., Choi, H. B., Martin, C., Lind, B. L., Khennouf, L., et al. (2017). A Critical Role for Astrocytes in Hypercapnic Vasodilation in Brain. J. Neurosci. 37, 2403-2414. doi: 10.1523/JNEUROSCI.0005-16.2016

Hu, M. Y., Lin, Y. Y., Zhang, B. J., Lu, D. L., Lu, Z. Q., and Cai, W. (2019). Update of inflammasome activation in microglia/macrophage in aging and aging-related disease. CNS Neurosci. Ther. 25, 1299-1307. doi: 10.1111/cns.13262

Huang, B. R., Liu, Y. S., Lai, S. W., Lin, H. J., Shen, C. K., Yang, L. Y., et al. (2020). CAIX Regulates GBM Motility and TAM Adhesion and Polarization through EGFR/STAT3 under Hypoxic Conditions. Int. J. Mol. Sci. 21:5838. doi: $10.3390 / \mathrm{ijms} 21165838$

Huang, P. L., Huang, Z., Mashimo, H., Bloch, K. D., Moskowitz, M. A., Bevan, J. A., et al. (1995). Hypertension in mice lacking the gene for endothelial nitric oxide synthase. Nature 377, 239-242. doi: 10.1038/377239a0

Huneau, C., Benali, H., and Chabriat, H. (2015). Investigating Human Neurovascular Coupling Using Functional Neuroimaging: a Critical Review of Dynamic Models. Front. Neurosci. 9:467. doi: 10.3389/fnins.2015.00467 
Iadecola, C. (2010). The overlap between neurodegenerative and vascular factors in the pathogenesis of dementia. Acta Neuropathol. 120, 287-296. doi: 10.1007/ s00401-010-0718-6

Iadecola, C. (2017). The Neurovascular Unit Coming of Age: a Journey through Neurovascular Coupling in Health and Disease. Neuron 96, 17-42. doi: 10. 1016/j.neuron.2017.07.030

Iadecola, C., and Nedergaard, M. (2007). Glial regulation of the cerebral microvasculature. Nat. Neurosci. 10, 1369-1376. doi: 10.1038/nn2003

Ilies, M., Banciu, M. D., Ilies, M. A., Scozzafava, A., Caproiu, M. T., and Supuran, C. T. (2002). Carbonic anhydrase activators: design of high affinity isozymes I, II, and IV activators, incorporating tri-/tetrasubstituted-pyridinium-azole moieties. J. Med. Chem. 45, 504-510. doi: 10.1021/jm011031n

Ilies, M. A., Masereel, B., Rolin, S., Scozzafava, A., Câmpeanu, G., Cîmpeanu, V., et al. (2004). Carbonic anhydrase inhibitors: aromatic and heterocyclic sulfonamides incorporating adamantyl moieties with strong anticonvulsant activity. Bioorg. Med. Chem. 12, 2717-2726. doi: 10.1016/j.bmc.2004.03.008

Ilies, M. A., Vullo, D., Pastorek, J., Scozzafava, A., Ilies, M., Caproiu, M. T., et al. (2003). Carbonic anhydrase inhibitors. Inhibition of tumor-associated isozyme IX by halogenosulfanilamide and halogenophenylaminobenzolamide derivatives. J. Med. Chem. 46, 2187-2196. doi: 10.1021/jm021123s

Ilies, M. A., and Winum, J.-Y. (2019). "Chapter 16 - Carbonic anhydrase inhibitors for the treatment of tumors: therapeutic, immunologic, and diagnostic tools targeting isoforms IX and XII" in Carbonic Anhydrases. eds C. T. Supuran and A. Nocentini (United States: Academic Press). 331-365. doi: 10.1016/B978-012-816476-1.00016-2

Iliff, J. J., Wang, M., Liao, Y., Plogg, B. A., Peng, W., Gundersen, G. A., et al. (2012). A paravascular pathway facilitates CSF flow through the brain parenchyma and the clearance of interstitial solutes, including amyloid $\beta$. Sci. Transl. Med. 4, 147ra111. doi: 10.1126/scitranslmed. 3003748

Imtaiyaz Hassan, M., Shajee, B., Waheed, A., Ahmad, F., and Sly, W. S. (2013). Structure, function and applications of carbonic anhydrase isozymes. Bioorg. Med. Chem. 21, 1570-1582. doi: 10.1016/j.bmc.2012.04.044

Ivanov, S., Liao, S. Y., Ivanova, A., Danilkovitch-Miagkova, A., Tarasova, N., Weirich, G., et al. (2001). Expression of hypoxia-inducible cell-surface transmembrane carbonic anhydrases in human cancer. Am. J. Pathol. 158, 905-919. doi: 10.1016/S0002-9440(10)64038-2

Ivanov, S. V., Kuzmin, I., Wei, M.-H., Pack, S., Geil, L., Johnson, B. E., et al. (1998). Down-regulation of transmembrane carbonic anhydrases in renal cell carcinoma cell lines by wild-type von Hippel-Lindau transgenes. Proc. Natl. Acad. Sci. 95:12596. doi: 10.1073/pnas.95.21.12596

Jiang, C. T., Wu, W. F., Deng, Y. H., and Ge, J. W. (2020). Modulators of microglia activation and polarization in ischemic stroke (Review). Mol. Med. Rep. 21, 2006-2018. doi: 10.3892/mmr.2020.11003

Jiao, H., Wang, Z., Liu, Y., Wang, P., and Xue, Y. (2011). Specific role of tight junction proteins claudin-5, occludin, and ZO-1 of the blood-brain barrier in a focal cerebral ischemic insult. J. Mol. Neurosci. 44, 130-139. doi: 10.1007/ s12031-011-9496-4

Johnson, B. A. (2005). Recent advances in the development of treatments for alcohol and cocaine dependence: focus on topiramate and other modulators of GABA or glutamate function. CNS Drugs 19, 873-896. doi: 10.2165/00023210200519100-00005

Joshi, A. U., Minhas, P. S., Liddelow, S. A., Haileselassie, B., Andreasson, K. I., Dorn, G. W. II, et al. (2019). Fragmented mitochondria released from microglia trigger $\mathrm{A} 1$ astrocytic response and propagate inflammatory neurodegeneration. Nat. Neurosci. 22, 1635-1648. doi: 10.1038/s41593-019-0486-0

Kang, M., and Yao, Y. (2020). Basement Membrane Changes in Ischemic Stroke. Stroke 51, 1344-1352. doi: 10.1161/STROKEAHA.120.028928

Kaplan, L., Chow, B. W., and Gu, C. (2020). Neuronal regulation of the bloodbrain barrier and neurovascular coupling. Nat. Rev. Neurosci. 21, 416-432. doi: 10.1038/s41583-020-0322-2

Kida, E., Palminiello, S., Golabek, A. A., Walus, M., Wierzba-Bobrowicz, T., Rabe, A., et al. (2006). Carbonic anhydrase II in the developing and adult human brain. J. Neuropathol. Exp. Neurol. 65, 664-674. doi: 10.1097/01.jnen. 0000225905.52002.3e

Kim, S. H., Ahn, J. H., Yang, H., Lee, P., Koh, G. Y., and Jeong, Y. (2020). Cerebral amyloid angiopathy aggravates perivascular clearance impairment in an Alzheimer's disease mouse model. Acta Neuropathol. Commun. 8:181. doi: 10.1186/s40478-020-01042-0
Kiss, B., Dallinger, S., Findl, O., Rainer, G., Eichler, H. G., and Schmetterer, L. (1999). Acetazolamide-induced cerebral and ocular vasodilation in humans is independent of nitric oxide. Am. J. Physiol. 276, R1661-R1667. doi: 10.1152/ ajpregu.1999.276.6.R1661

Knopman, D. S., Jones, D. T., and Greicius, M. D. (2021). Failure to demonstrate efficacy of aducanumab: an analysis of the EMERGE and ENGAGE trials as reported by Biogen. December 2019. Alzheimers Dement. 17, 696-701. doi: 10.1002/alz.12213

Krishnamurthy, V. M., Kaufman, G. K., Urbach, A. R., Gitlin, I., Gudiksen, K. L., Weibel, D. B., et al. (2008). Carbonic Anhydrase as a Model for Biophysical and Physical-Organic Studies of Proteins and Protein-Ligand Binding. Chem. Rev. 108, 946-1051. doi: 10.1021/cr050262p

Kuriakose, D., and Xiao, Z. (2020). Pathophysiology and Treatment of Stroke: present Status and Future Perspectives. Int. J. Mol. Sci. 21:7609. doi: 10.3390/ ijms 21207609

Kuźma, E., Lourida, I., Moore, S. F., Levine, D. A., Ukoumunne, O. C., and Llewellyn, D. J. (2018). Stroke and dementia risk: A systematic review and meta-analysis. Alzheimers Dement. 14, 1416-1426. doi: 10.1016/j.jalz.2018.06. 3061

Li, M., Wang, W., Mai, H., Zhang, X., Wang, J., Gao, Y., et al. (2016). Methazolamide improves neurological behavior by inhibition of neuron apoptosis in subarachnoid hemorrhage mice. Sci. Rep. 6:35055. doi: 10.1038/ srep35055

Liddelow, S. A., Guttenplan, K. A., Clarke, L. E., Bennett, F. C., Bohlen, C. J., Schirmer, L., et al. (2017). Neurotoxic reactive astrocytes are induced by activated microglia. Nature 541, 481-487. doi: 10.1038/nature21029

Liu, C., Wei, Y., Wang, J., Pi, L., Huang, J., and Wang, P. (2012). Carbonic anhydrases III and IV autoantibodies in rheumatoid arthritis, systemic lupus erythematosus, diabetes, hypertensive renal disease, and heart failure. Clin. Dev. Immunol. 2012:354594. doi: 10.1155/2012/354594

Lochhead, J. J., Mccaffrey, G., Quigley, C. E., Finch, J., Demarco, K. M., Nametz, N., et al. (2010). Oxidative stress increases blood-brain barrier permeability and induces alterations in occludin during hypoxia-reoxygenation. J. Cereb. Blood Flow Metab. 30, 1625-1636. doi: 10.1038/jcbfm.2010.29

Lok, J., Wang, X. S., Xing, C. H., Maki, T. K., Wu, L. M., Guo, S. Z., et al. (2015). Targeting the neurovascular unit in brain trauma. CNS Neurosci. Ther. 21, 304-308. doi: 10.1111/cns.12359

Lorenzl, S., Albers, D. S., Relkin, N., Ngyuen, T., Hilgenberg, S. L., Chirichigno, J., et al. (2003). Increased plasma levels of matrix metalloproteinase- 9 in patients with Alzheimer's disease. Neurochem. Int. 43, 191-196. doi: 10.1016/S01970186(03)00004-4

Lu, H., Zhang, H., and Jiang, Y. (2020). Methazolamide in high-altitude illnesses. Eur. J. Pharm. Sci. 148:105326. doi: 10.1016/j.ejps.2020.105326

Manley, G. T., Fujimura, M., Ma, T., Noshita, N., Filiz, F., Bollen, A. W., et al. (2000). Aquaporin-4 deletion in mice reduces brain edema after acute water intoxication and ischemic stroke. Nat. Med. 6, 159-163. doi: 10.1038/72256

Mao, X. Y., Cao, Y. G., Ji, Z., Zhou, H. H., Liu, Z. Q., and Sun, H. L. (2015). Topiramate protects against glutamate excitotoxicity via activating BDNF/TrkB-dependent ERK pathway in rodent hippocampal neurons. Prog. Neuropsychopharmacol. Biol. Psychiatry 60, 11-17. doi: 10.1016/j.pnpbp.2015. 01.015

Marco, S., and Skaper, S. D. (2006). Amyloid beta-peptide1-42 alters tight junction protein distribution and expression in brain microvessel endothelial cells. Neurosci. Lett. 401, 219-224. doi: 10.1016/j.neulet.2006.03.047

Maren, T. H. (1967). Carbonic anhydrase: chemistry, physiology, and inhibition. Physiol. Rev. 47, 595-781. doi: 10.1152/physrev.1967.47.4.595

Mboge, M. Y., Mahon, B. P., Mckenna, R., and Frost, S. C. (2018). Carbonic Anhydrases: role in $\mathrm{pH}$ Control and Cancer. Metabolites 8:19. doi: 10.3390/ metabo8010019

McAlpine, C. S., Park, J., Griciuc, A., Kim, E., Choi, S. H., Iwamoto, Y., et al. (2021). Astrocytic interleukin-3 programs microglia and limits Alzheimer's disease. Nature 595, 701-706. doi: 10.1038/s41586-021-03734-6

McConnell, H. L., Li, Z., Woltjer, R. L., and Mishra, A. (2019). Astrocyte dysfunction and neurovascular impairment in neurological disorders: correlation or causation? Neurochem. Int. 128, 70-84. doi: 10.1016/j.neuint. 2019.04.005

McDonald, P. C., Chia, S., Bedard, P. L., Chu, Q., Lyle, M., Tang, L., et al. (2020). A Phase 1 Study of SLC-0111, a Novel Inhibitor of Carbonic Anhydrase IX, 
in Patients With Advanced Solid Tumors. Am. J. Clin. Oncol. 43, 484-490. doi: 10.1097/COC.0000000000000691

McKenna, R., and Supuran, C. T. (2014). Carbonic anhydrase inhibitors drug design. Subcell. Biochem. 75, 291-323. doi: 10.1007/978-94-007-7359-2_15

Mestre, H., Mori, Y., and Nedergaard, M. (2020). The Brain's Glymphatic System: current Controversies. Trends Neurosci. 43, 458-466. doi: 10.1016/j.tins.2020. 04.003

Mincione, F., Scozzafava, A., and Supuran, C. T. (2007). The development of topically acting carbonic anhydrase inhibitors as anti-glaucoma agents. Curr. Top. Med. Chem. 7, 849-854. doi: 10.2174/156802607780636735

Mishra, C. B., Tiwari, M., and Supuran, C. T. (2020). Progress in the development of human carbonic anhydrase inhibitors and their pharmacological applications: where are we today? Med. Res. Rev. 40, 2485-2565. doi: 10.1002/med.21713

Mohamed, I. N., Ishrat, T., Fagan, S. C., and El-Remessy, A. B. (2015). Role of inflammasome activation in the pathophysiology of vascular diseases of the neurovascular unit. Antioxid. Redox Signal. 22, 1188-1206. doi: 10.1089/ars. 2014.6126

Montaner, J., Ramiro, L., Simats, A., Hernandez-Guillamon, M., Delgado, P., Bustamante, A., et al. (2019). Matrix metalloproteinases and ADAMs in stroke. Cell. Mol. Life Sci. 76, 3117-3140. doi: 10.1007/s00018-019-0 3175-5

Mori, K., Ogawa, Y., Ebihara, K., Tamura, N., Tashiro, K., Kuwahara, T., et al. (1999). Isolation and characterization of CA XIV, a novel membrane-bound carbonic anhydrase from mouse kidney. J. Biol. Chem. 274, 15701-15705. doi: $10.1074 /$ jbc. 274.22 .15701

Morikawa, E., Moskowitz, M. A., Huang, Z., Yoshida, T., Irikura, K., and Dalkara, T. (1994). L-arginine infusion promotes nitric oxide-dependent vasodilation, increases regional cerebral blood flow, and reduces infarction volume in the rat. Stroke 25, 429-435. doi: 10.1161/01.STR.25.2.429

Morris, A. W., Carare, R. O., Schreiber, S., and Hawkes, C. A. (2014). The Cerebrovascular Basement Membrane: role in the Clearance of $\beta$-amyloid and Cerebral Amyloid Angiopathy. Front. Aging Neurosci. 6:251. doi: 10.3389/fnagi. 2014.00251

Nedergaard, M., and Goldman, S. A. (2020). Glymphatic failure as a final common pathway to dementia. Science 370, 50-56. doi: 10.1126/science.abb8739

Nishimori, I., Minakuchi, T., Onishi, S., Vullo, D., Scozzafava, A., and Supuran, C. T. (2007). Carbonic anhydrase inhibitors. DNA cloning, characterization, and inhibition studies of the human secretory isoform VI, a new target for sulfonamide and sulfamate inhibitors. J. Med. Chem. 50, 381-388. doi: 10.1021/ jm0612057

Nishimori, I., Vullo, D., Innocenti, A., Scozzafava, A., Mastrolorenzo, A., and Supuran, C. T. (2005). Carbonic anhydrase inhibitors. The mitochondrial isozyme VB as a new target for sulfonamide and sulfamate inhibitors. J. Med. Chem. 48, 7860-7866. doi: 10.1021/jm050483n

Nortley, R., Korte, N., Izquierdo, P., Hirunpattarasilp, C., Mishra, A., Jaunmuktane, Z., et al. (2019). Amyloid $\beta$ oligomers constrict human capillaries in Alzheimer's disease via signaling to pericytes. Science 365:eaav9518. doi: 10.1126/science. aav9518

Oeckl, P., Halbgebauer, S., Anderl-Straub, S., Steinacker, P., Huss, A. M., and Neugebauer, H. (2019). Glial Fibrillary Acidic Protein in Serum is Increased in Alzheimer's Disease and Correlates with Cognitive Impairment. J. Alzheimers Dis. 67, 481-488. doi: 10.3233/JAD-180325

Ojo, J. O., Reed, J. M., Crynen, G., Vallabhaneni, P., Evans, J., Shackleton, B., et al. (2021). Molecular Pathobiology of the Cerebrovasculature in Aging and in Alzheimers Disease Cases With Cerebral Amyloid Angiopathy. Front. Aging Neurosci. 13:658605. doi: 10.3389/fnagi.2021.658605

Okudaira, Y., Bandoh, K., Arai, H., and Sato, K. (1995). Evaluation of the acetazolamide test. Vasoreactivity and cerebral blood volume. Stroke 26, 12341239. doi: 10.1161/01.STR.26.7.1234

Oldendorf, W. H., Cornford, M. E., and Brown, W. J. (1977). The large apparent work capability of the blood-brain barrier: a study of the mitochondrial content of capillary endothelial cells in brain and other tissues of the rat. Ann. Neurol. 1, 409-417. doi: 10.1002/ana.410010502

Pan, P., Leppilampi, M., Pastorekova, S., Pastorek, J., Waheed, A., Sly, W. S., et al. (2006). Carbonic anhydrase gene expression in CA II-deficient (Car2-/-) and CA IX-deficient (Car9-/-) mice. J. Physiol. 571, 319-327. doi: 10.1113/jphysiol. 2005.102590
Pan, P. W., Parkkila, A. K., Autio, S., Hilvo, M., Sormunen, R., Pastorekova, S., et al. (2012). Brain phenotype of carbonic anhydrase IX-deficient mice. Transgenic Res. 21, 163-176. doi: 10.1007/s11248-011-9520-z

Parodi-Rullán, R., Ghiso, J., Cabrera, E., Rostagno, A., and Fossati, S. (2020). Alzheimer's amyloid $\beta$ heterogeneous species differentially affect brain endothelial cell viability, blood-brain barrier integrity, and angiogenesis. Aging Cell. 19:e13258. doi: 10.1111/acel.13258

Parodi-Rullán, R., Sone, J. Y., and Fossati, S. (2019). Endothelial Mitochondrial Dysfunction in Cerebral Amyloid Angiopathy and Alzheimer's Disease. J. Alzheimers Dis. 72, 1019-1039. doi: 10.3233/JAD-190357

Pastorek, J., and Pastorekova, S. (2015). Hypoxia-induced carbonic anhydrase IX as a target for cancer therapy: from biology to clinical use. Semin. Cancer Biol. 31, 52-64. doi: 10.1016/j.semcancer.2014.08.002

Patrick, P., Price, T. O., Diogo, A. L., Sheibani, N., Banks, W. A., and Shah, G. N. (2015). Topiramate Protects Pericytes from Glucotoxicity: role for Mitochondrial CA VA in Cerebromicrovascular Disease in Diabetes. J. Endocrinol. Diabetes 2, 1-7. doi: 10.15226/2374-6890/2/2/00123

Patrikainen, M., Pan, P., Kulesskaya, N., Voikar, V., and Parkkila, S. (2014). The role of carbonic anhydrase VI in bitter taste perception: evidence from the Car6 ${ }^{-} /^{-}$mouse model. J. Biomed. Sci. 21, 82. doi: 10.1186/s12929-014-0082-2

Pavics, L., Grunwald, F., Reichmann, K., Horn, R., Kitschenberg, A., Hartmann, A., et al. (1999). Regional cerebral blood flow single-photon emission tomography with $99 \mathrm{mTc}-\mathrm{HMPAO}$ and the acetazolamide test in the evaluation of vascular and Alzheimer's dementia. Eur. J. Nucl. Med. 26, 239-245. doi: 10.1007/ s002590050383

Pekny, M., and Lane, E. B. (2007). Intermediate filaments and stress. Exp. Cell Res. 313, 2244-2254. doi: 10.1016/j.yexcr.2007.04.023

Pollard, A., Shephard, F., Freed, J., Liddell, S., and Chakrabarti, L. (2016). Mitochondrial proteomic profiling reveals increased carbonic anhydrase II in aging and neurodegeneration. Aging 8, 2425-2436. doi: 10.18632/aging.101064

Price, T. O., Eranki, V., Banks, W. A., Ercal, N., and Shah, G. N. (2012). Topiramate treatment protects blood-brain barrier pericytes from hyperglycemia-induced oxidative damage in diabetic mice. Endocrinology 153, 362-372. doi: 10.1210/ en.2011-1638

Price, T. O., Sheibani, N., and Shah, G. N. (2017). Regulation of high glucoseinduced apoptosis of brain pericytes by mitochondrial CA VA: a specific target for prevention of diabetic cerebrovascular pathology. Biochim. Biophys. Acta Mol. Basis Dis. 1863, 929-935. doi: 10.1016/j.bbadis.2017.01.025

Proescholdt, M. A., Mayer, C., Kubitza, M., Schubert, T., Liao, S.-Y., Stanbridge, E. J., et al. (2005). Expression of hypoxia-inducible carbonic anhydrases in brain tumors. Neurooncology 7, 465-475. doi: 10.1215/S1152851705000025

Provensi, G., Carta, F., Nocentini, A., Supuran, C. T., Casamenti, F., Passani, M. B., et al. (2019). A New Kid on the Block? Carbonic Anhydrases as Possible New Targets in Alzheimer's Disease. Int J Mol Sci 20:4724. doi: 10.3390/ ijms20194724

Pun, P. B., Lu, J., and Moochhala, S. (2009). Involvement of ROS in BBB dysfunction. Free Radic. Res. 43, 348-364. doi: 10.1080/10715760902751902

Purkerson, J. M., and Schwartz, G. J. (2007). The role of carbonic anhydrases in renal physiology. Kidney Int. 71, 103-115. doi: 10.1038/sj.ki.5002020

Quintana, D. D., Anantula, Y., Garcia, J. A., Engler-Chiurazzi, E. B., Sarkar, S. N., Corbin, D. R., et al. (2021). Microvascular degeneration occurs before plaque onset and progresses with age in 3xTg AD mice. Neurobiol. Aging 105, 115-128. doi: 10.1016/j.neurobiolaging.2021.04.019

Radenovic, L., Nenadic, M., Ułamek-Kozioł, M., Januszewski, S., Czuczwar, S. J., Andjus, P. R., et al. (2020). Heterogeneity in brain distribution of activated microglia and astrocytes in a rat ischemic model of Alzheimer's disease after 2 years of survival. Aging 12, 12251-12267. doi: 10.18632/aging.103411

Rasmussen, J. K., and Boedtkjer, E. (2018). Carbonic anhydrase inhibitors modify intracellular $\mathrm{pH}$ transients and contractions of rat middle cerebral arteries during CO. J. Cereb. Blood Flow Metab. 38, 492-505. doi: 10.1177/ $0271678 X 17699224$

Reese, T. S., and Karnovsky, M. J. (1967). Fine structural localization of a bloodbrain barrier to exogenous peroxidase. J. Cell. Biol. 34, 207-217. doi: 10.1083/ jcb.34.1.207

Ritchie, N. D., Baggott, A. V., and Andrew Todd, W. T. (2012). Acetazolamide for the prevention of acute mountain sickness-a systematic review and meta-analysis. J. Travel Med. 19, 298-307. doi: 10.1111/j.1708-8305.2012.0 0629.x 
Russell, S. M., Woo, H. H., Siller, K., Panasci, D., and Leroux, P. D. (2008). Evaluating middle cerebral artery collateral blood flow reserve using acetazolamide transcranial Doppler ultrasound in patients with carotid occlusive disease. Surg. Neurol. 70, 466-470. doi: 10.1016/j.surneu.2007.10.030

Ruusuvuori, E., Huebner, A. K., Kirilkin, I., Yukin, A. Y., Blaesse, P., Helmy, M., et al. (2013). Neuronal carbonic anhydrase VII provides GABAergic excitatory drive to exacerbate febrile seizures. Embo J. 32, 2275-2286. doi: 10.1038/emboj. 2013.160

Ruusuvuori, E., and Kaila, K. (2014). Carbonic anhydrases and brain $\mathrm{pH}$ in the control of neuronal excitability. Subcell. Biochem. 75, 271-290. doi: 10.1007/ 978-94-007-7359-2_14

Ruusuvuori, E., Li, H., Huttu, K., Palva, J. M., Smirnov, S., Rivera, C., et al. (2004). Carbonic anhydrase isoform VII acts as a molecular switch in the development of synchronous gamma-frequency firing of hippocampal CA1 pyramidal cells. J. Neurosci. 24, 2699-2707. doi: 10.1523/JNEUROSCI.5176-03.2004

Saarnio, J., Parkkila, S., Parkkila, A. K., Waheed, A., Casey, M. C., Zhou, X. Y., et al. (1998). Immunohistochemistry of carbonic anhydrase isozyme IX (MN/CA IX) in human gut reveals polarized expression in the epithelial cells with the highest proliferative capacity. J. Histochem. Cytochem. 46, 497-504. doi: 10. 1177/002215549804600409

Sacco, R. L., Kasner, S. E., Broderick, J. P., Caplan, L. R., Connors, J. J., Culebras, A., et al. (2013). An updated definition of stroke for the 21st century: a statement for healthcare professionals from the American Heart Association/American Stroke Association. Stroke 44, 2064-2089. doi: 10.1161/STR.0b013e318296aeca

Sagare, A. P., Bell, R. D., Zhao, Z., Ma, Q., Winkler, E. A., Ramanathan, A., et al. (2013). Pericyte loss influences Alzheimer-like neurodegeneration in mice. Nat. Commun. 4:2932. doi: 10.1038/ncomms3932

Salameh, T. S., Mortell, W. G., Logsdon, A. F., Butterfield, D. A., and Banks, W. A. (2019). Disruption of the hippocampal and hypothalamic blood-brain barrier in a diet-induced obese model of type II diabetes: prevention and treatment by the mitochondrial carbonic anhydrase inhibitor, topiramate. Fluids Barriers CNS 16:1. doi: 10.1186/s12987-018-0121-6

Salameh, T. S., Shah, G. N., Price, T. O., Hayden, M. R., and Banks, W. A. (2016). Blood-Brain Barrier Disruption and Neurovascular Unit Dysfunction in Diabetic Mice: protection with the Mitochondrial Carbonic Anhydrase Inhibitor Topiramate. J. Pharmacol. Exp. Ther. 359, 452-459. doi: 10.1124/jpet. 116.237057

Sanku, R. K. K., John, J. S., Salkovitz, M., Ilies, M. A., and Walker, E. A. (2018). Potential learning and memory disruptors and enhancers in a simple, 1-day operant task in mice. Behav. Pharmacol. 29, 482-492. doi: 10.1097/FBP. 0000000000000400

Sarvari, S., Moakedi, F., Hone, E., Simpkins, J. W., and Ren, X. (2020). Mechanisms in blood-brain barrier opening and metabolism-challenged cerebrovascular ischemia with emphasis on ischemic stroke. Metab. Brain Dis. 35, 851-868. doi: 10.1007/s11011-020-00573-8

Savva, G. M., and Stephan, B. C. (2010). Epidemiological studies of the effect of stroke on incident dementia: a systematic review. Stroke 41, e41-46. doi: 10.1161/STROKEAHA.109.559880

Schmidt, S. D., Costa, A., Rani, B., Godfried Nachtigall, E., Passani, M. B., Carta, F., et al. (2020). The role of carbonic anhydrases in extinction of contextual fear memory. Proc. Natl. Acad. Sci. U. S. A. 117, 16000-16008. doi: 10.1073/pnas. 1910690117

Schreibelt, G., Kooij, G., Reijerkerk, A., Van Doorn, R., Gringhuis, S. I., Van Der Pol, S., et al. (2007). Reactive oxygen species alter brain endothelial tight junction dynamics via RhoA. PI3 kinase, and PKB signaling. FASEB J. 21, 3666-3676. doi: 10.1096/fj.07-8329com

Scozzafava, A., Briganti, F., Ilies, M. A., and Supuran, C. T. (2000). Carbonic anhydrase inhibitors: synthesis of membrane-impermeant low molecular weight sulfonamides possessing in vivo selectivity for the membrane-bound versus cytosolic isozymes. J. Med. Chem. 43, 292-300. doi: 10.1021/jm990479+

Scozzafava, A., Supuran, C. T., and Carta, F. (2013). Antiobesity carbonic anhydrase inhibitors: a literature and patent review. Expert. Opin. Ther. Pat. 23, 725-735. doi: 10.1517/13543776.2013.790957

Seçkin, H., Simşek, S., Oztürk, E., Yigitkanli, K., Ozen, O., Beşalti, O., et al. (2009). Topiramate attenuates hippocampal injury after experimental subarachnoid hemorrhage in rabbits. Neurol. Res. 31, 490-495. doi: 10.1179/ 016164108X339369
Sekerdag, E., Solaroglu, I., and Gursoy-Ozdemir, Y. (2018). Cell Death Mechanisms in Stroke and Novel Molecular and Cellular Treatment Options. Curr. Neuropharmacol. 16, 1396-1415. doi: 10.2174/1570159X16666180302115544

Sevigny, J., Chiao, P., Bussiere, T., Weinreb, P. H., Williams, L., Maier, M., et al. (2017). Addendum: The antibody aducanumab reduces Abeta plaques in Alzheimer's disease. Nature 546:564. doi: 10.1038/nature22809

Shabana, A. M., and Ilies, M. A. (2019). Drug Delivery to Hypoxic Tumors Targeting Carbonic Anhydrase IX. United States: American Chemical Society. 223-252. doi: 10.1021/bk-2019-1309.ch010

Shah, G. N., Hewett-Emmett, D., Grubb, J. H., Migas, M. C., Fleming, R. E., Waheed, A., et al. (2000). Mitochondrial carbonic anhydrase CA VB: differences in tissue distribution and pattern of evolution from those of CA VA suggest distinct physiological roles. Proc. Natl. Acad. Sci. U. S. A. 97, 1677-1682. doi: 10.1073/pnas.97.4.1677

Shah, G. N., Morofuji, Y., Banks, W. A., and Price, T. O. (2013a). High glucoseinduced mitochondrial respiration and reactive oxygen species in mouse cerebral pericytes is reversed by pharmacological inhibition of mitochondrial carbonic anhydrases: implications for cerebral microvascular disease in diabetes. Biochem. Biophys. Res. Commun. 440, 354-358. doi: 10.1016/j.bbrc. 2013.09.086

Shah, G. N., Rubbelke, T. S., Hendin, J., Nguyen, H., Waheed, A., Shoemaker, J. D., et al. (2013b). Targeted mutagenesis of mitochondrial carbonic anhydrases VA and VB implicates both enzymes in ammonia detoxification and glucose metabolism. Proc. Natl. Acad. Sci. U. S. A. 110, 7423-7428. doi: 10.1073/pnas. 1305805110

Shah, G. N., Ulmasov, B., Waheed, A., Becker, T., Makani, S., Svichar, N., et al. (2005). Carbonic anhydrase IV and XIV knockout mice: roles of the respective carbonic anhydrases in buffering the extracellular space in brain. Proc. Natl. Acad. Sci. U. S. A. 102, 16771-16776. doi: 10.1073/pnas.0508449102

Shin, J. A., Yoon, J. C., Kim, M., and Park, E. M. (2016). Activation of classical estrogen receptor subtypes reduces tight junction disruption of brain endothelial cells under ischemia/reperfusion injury. Free Radic. Biol. Med. 92, 78-89. doi: 10.1016/j.freeradbiomed.2016.01.010

Silverman, D. N., and Lindskog, S. (1988). The catalytic mechanism of carbonic anhydrase: implications of a rate-limiting protolysis of water. Acc. Chem. Res. 21, 30-36. doi: 10.1021/ar00145a005

Sly, W. S., and Hu, P. Y. (1995). Human carbonic anhydrases and carbonic anhydrase deficiencies. Annu. Rev. Biochem. 64, 375-401. doi: 10.1146/ annurev.bi.64.070195.002111

Smaine, F. Z., Winum, J. Y., Montero, J. L., Regainia, Z., Vullo, D., Scozzafava, A., et al. (2007). Carbonic anhydrase inhibitors: selective inhibition of the extracellular, tumor-associated isoforms IX and XII over isozymes I and II with glycosyl-thioureido-sulfonamides. Bioorg. Med. Chem. Lett. 17, 5096-5100. doi: 10.1016/j.bmcl.2007.07.019

Smith, A. J., Duan, T., and Verkman, A. S. (2019). Aquaporin-4 reduces neuropathology in a mouse model of Alzheimer's disease by remodeling periplaque astrocyte structure. Acta Neuropathol. Commun. 7:74. doi: 10.1186/ s40478-019-0728-0

Solesio, M. E., Peixoto, P. M., Debure, L., Madamba, S. M., De Leon, M. J., Wisniewski, T., et al. (2018). Carbonic anhydrase inhibition selectively prevents amyloid $\beta$ neurovascular mitochondrial toxicity. Aging Cell. 17:e12787. doi: 10.1111/acel.12787

Sotolongo, K., Ghiso, J., and Rostagno, A. (2020). Nrf2 activation through the PI3K/GSK-3 axis protects neuronal cells from Abeta-mediated oxidative and metabolic damage. Alzheimers Res. Ther. 12:13. doi: 10.1186/s13195-019 $-0578-9$

Stams, T., Nair, S. K., Okuyama, T., Waheed, A., Sly, W. S., and Christianson, D. W. (1996). Crystal structure of the secretory form of membrane-associated human carbonic anhydrase IV at 2.8-A resolution. Proc. Natl. Acad. Sci. U. S. A. 93, 13589-13594. doi: 10.1073/pnas.93.24.13589

Stoppe, G., Schutze, R., Kogler, A., Staedt, J., Munz, D. L., Emrich, D., et al. (1995). Cerebrovascular reactivity to acetazolamide in (senile) dementia of Alzheimer's type: relationship to disease severity. Dementia 6, 73-82. doi: $10.1159 / 000106925$

Supuran, C. T. (2008). Carbonic anhydrases: novel therapeutic applications for inhibitors and activators. Nat. Rev. Drug Discov. 7, 168-181. doi: 10.1038/ $\operatorname{nrd} 2467$ 
Supuran, C. T. (2011). Carbonic anhydrase inhibitors and activators for novel therapeutic applications. Future Med. Chem. 3, 1165-1180. doi: 10.4155/fmc. 11.69

Supuran, C. T. (2012). Carbonic anhydrase inhibitors as emerging drugs for the treatment of obesity. Expert Opin. Emerg. Drugs 17, 11-15. doi: 10.1517/ 14728214.2012 .664132

Supuran, C. T. (2018). Applications of carbonic anhydrases inhibitors in renal and central nervous system diseases. Expert Opin. Ther. Pat. 28, 713-721. doi: 10.1080/13543776.2018.1519023

Supuran, C. T., and Capasso, C. (2020). Antibacterial carbonic anhydrase inhibitors: an update on the recent literature. Expert Opin. Ther. Pat. 30, 963-982. doi: 10.1080/13543776.2020.1811853

Supuran, C. T., Scozzafava, A., and Casini, A. (2003). Carbonic anhydrase inhibitors. Med. Res. Rev. 23, 146-189. doi: 10.1002/med.10025

Supuran, C. T., Scozzafava, A., Ilies, M. A., Iorga, B., Cristea, T., Briganti, F., et al. (1998). Carbonic anhydrase inhibitors - Part 53. Synthesis of substitutedpyridinium derivatives of aromatic sulfonamides: the first non-polymeric membrane-impermeable inhibitors with selectivity for isozyme IV. Eur. J. Med. Chem. 33, 577-594. doi: 10.1016/S0223-5234(98)80017-2

Supuran, C. T., and Winum, J. Y. (2015). Carbonic anhydrase IX inhibitors in cancer therapy: an update. Future Med. Chem. 7, 1407-1414. doi: 10.4155/fmc. 15.71

Sweeney, M. D., Montagne, A., Sagare, A. P., Nation, D. A., Schneider, L. S., Chui, H. C., et al. (2019a). Vascular dysfunction-The disregarded partner of Alzheimer's disease. Alzheimers Dement. 15, 158-167.

Sweeney, M. D., Zhao, Z., Montagne, A., Nelson, A. R., and Zlokovic, B. V. (2019b). Blood-Brain Barrier: From Physiology to Disease and Back. Physiol. Rev. 99, 21-78. doi: 10.1152/physrev.00050.2017

Tang, M., Gao, G., Rueda, C. B., Yu, H., Thibodeaux, D. N., Awano, T., et al. (2017). Brain microvasculature defects and Glut1 deficiency syndrome averted by early repletion of the glucose transporter-1 protein. Nat. Commun. 8:14152. doi: $10.1038 /$ ncomms 14152

Tang, Y., and Le, W. (2016). Differential Roles of M1 and M2 Microglia in Neurodegenerative Diseases. Mol. Neurobiol. 53, 1181-1194. doi: 10.1007/ s12035-014-9070-5

Tuettenberg, J., Heimann, A., and Kempski, O. (2001). Nitric oxide modulates cerebral blood flow stimulation by acetazolamide in the rat cortex: a laser Doppler scanning study. Neurosci. Lett. 315, 65-68. doi: 10.1016/S03043940(01)02325-4

Türeci, Ö, Sahin, U., Vollmar, E., Siemer, S., Göttert, E., Seitz, G., et al. (1998). Human carbonic anhydrase XII: cDNA cloning, expression, and chromosomal localization of a carbonic anhydrase gene that is overexpressed in some renal cell cancers. Proc. Natl. Acad. Sci. 95:7608. doi: 10.1073/pnas.95.13.7608

Turner, R. J., and Sharp, F. R. (2016). Implications of MMP9 for Blood Brain Barrier Disruption and Hemorrhagic Transformation Following Ischemic Stroke. Front. Cell. Neurosci. 10:56. doi: 10.3389/fncel.2016. 00056

Ulland, T. K., and Colonna, M. (2018). TREM2 - a key player in microglial biology and Alzheimer disease. Nat. Rev. Neurol. 14, 667-675. doi: 10.1038/s41582018-0072-1

van Putten, M., Fahlke, C., Kafitz, K. W., Hofmeijer, J., and Rose, C. R. (2021). Dysregulation of Astrocyte Ion Homeostasis and Its Relevance for StrokeInduced Brain Damage. Int. J. Mol. Sci. 22:5679. doi: 10.3390/ijms22115679

Vargas, L. A., Pinilla, O. A., Díaz, R. G., Sepúlveda, D. E., Swenson, E. R., Pérez, N. G., et al. (2016). Carbonic anhydrase inhibitors reduce cardiac dysfunction after sustained coronary artery ligation in rats. Cardiovasc. Pathol. 25, 468-477. doi: 10.1016/j.carpath.2016.08.003

Venkateshappa, C., Harish, G., Mythri, R. B., Mahadevan, A., Bharath, M. M., and Shankar, S. K. (2012). Increased oxidative damage and decreased antioxidant function in aging human substantia nigra compared to striatum: implications for Parkinson's disease. Neurochem. Res. 37, 358-369. doi: 10.1007/s11064-0110619-7

Verkerke, M., Hol, E. M., and Middeldorp, J. (2021). Physiological and Pathological Ageing of Astrocytes in the Human Brain. Neurochem. Res. 46, 2662-2675. doi: 10.1007/s11064-021-03256-7
Villegas-Llerena, C., Phillips, A., Garcia-Reitboeck, P., Hardy, J., and Pocock, J. M. (2016). Microglial genes regulating neuroinflammation in the progression of Alzheimer's disease. Curr. Opin. Neurobiol. 36, 74-81. doi: 10.1016/j.conb.2015. 10.004

Waheed, A., and Sly, W. S. (2017). Carbonic anhydrase XII functions in health and disease. Gene 623, 33-40. doi: 10.1016/j.gene.2017.04.027

Wang, X., Figueroa, B. E., Stavrovskaya, I. G., Zhang, Y., Sirianni, A. C., Zhu, S., et al. (2009). Methazolamide and melatonin inhibit mitochondrial cytochrome $\mathrm{C}$ release and are neuroprotective in experimental models of ischemic injury. Stroke 40, 1877-1885. doi: 10.1161/STROKEAHA.108.540765

Wang, X., Zhu, S., Pei, Z., Drozda, M., Stavrovskaya, I. G., Del Signore, S. J., et al. (2008). Inhibitors of cytochrome c release with therapeutic potential for Huntington's disease. J. Neurosci. 28, 9473-9485. doi: 10.1523/JNEUROSCI. 1867-08.2008

Whittington, D. A., Waheed, A., Ulmasov, B., Shah, G. N., Grubb, J. H., Sly, W. S., et al. (2001). Crystal structure of the dimeric extracellular domain of human carbonic anhydrase XII, a bitopic membrane protein overexpressed in certain cancer tumor cells. Proc. Natl. Acad. Sci. U. S. A. 98, 9545-9550. doi: $10.1073 /$ pnas. 161301298

Willis, E. F., Macdonald, K. P. A., Nguyen, Q. H., Garrido, A. L., Gillespie, E. R., and Harley, S. B. R. (2020). Repopulating Microglia Promote Brain Repair in an IL-6-Dependent Manner. Cell 180, 833.e-846.e. doi: 10.1016/j.cell.2020.02.013

Winum, J. Y., Poulsen, S. A., and Supuran, C. T. (2009). Therapeutic applications of glycosidic carbonic anhydrase inhibitors. Med. Res. Rev. 29, 419-435. doi: 10.1002/med.20141

Xing, C., Hayakawa, K., Lok, J., Arai, K., and Lo, E. H. (2012). Injury and repair in the neurovascular unit. Neurol. Res. 34, 325-330. doi: 10.1179/1743132812Y. 0000000019

Yang, C., Hawkins, K. E., Doré, S., and Candelario-Jalil, E. (2019). Neuroinflammatory mechanisms of blood-brain barrier damage in ischemic stroke. Am. J. Physiol. Cell. Physiol. 316, C135-C153. doi: 10.1152/ajpcell.00136.2018

Yang, Y., and Rosenberg, G. A. (2015). Matrix metalloproteinases as therapeutic targets for stroke. Brain Res. 1623, 30-38. doi: 10.1016/j.brainres.2015.04.024

Yao, Y. (2019). Basement membrane and stroke. J. Cereb. Blood Flow Metab. 39, 3-19. doi: 10.1177/0271678X18801467

Zamanova, S., Shabana, A. M., Mondal, U. K., and Ilies, M. A. (2019). Carbonic anhydrases as disease markers. Expert. Opin. Ther. Pat. 29, 509-533. doi: 10.1080/13543776.2019.1629419

Zhou, Y., Song, W. M., Andhey, P. S., Swain, A., Levy, T., Miller, K. R., et al. (2020). Human and mouse single-nucleus transcriptomics reveal TREM2-dependent and TREM2-independent cellular responses in Alzheimer's disease. Nat. Med. 26, 131-142. doi: 10.1038/s41591-019-0695-9

Zlokovic, B. V., Gottesman, R. F., Bernstein, K. E., Seshadri, S., Mckee, A., Snyder, H., et al. (2020). Vascular contributions to cognitive impairment and dementia (VCID): a report from the 2018 National Heart, Lung, and Blood Institute and National Institute of Neurological Disorders and Stroke Workshop. Alzheimers Dement. 16, 1714-1733. doi: 10.1002/alz.12157

Conflict of Interest: The authors declare that the research was conducted in the absence of any commercial or financial relationships that could be construed as a potential conflict of interest.

Publisher's Note: All claims expressed in this article are solely those of the authors and do not necessarily represent those of their affiliated organizations, or those of the publisher, the editors and the reviewers. Any product that may be evaluated in this article, or claim that may be made by its manufacturer, is not guaranteed or endorsed by the publisher.

Copyright (c) 2021 Lemon, Canepa, Ilies and Fossati. This is an open-access article distributed under the terms of the Creative Commons Attribution License (CC BY). The use, distribution or reproduction in other forums is permitted, provided the original author(s) and the copyright owner(s) are credited and that the original publication in this journal is cited, in accordance with accepted academic practice. No use, distribution or reproduction is permitted which does not comply with these terms. 